\title{
DEVELOPMENT OF AN IMPLEMENTATION PLAN FOR ATMOSPHERIC CARBON MONITORING IN CALIFORNIA
}

\author{
Prepared For: \\ California Energy Commission \\ Public Interest Energy Research Program \\ Prepared By: \\ E.O. Lawrence Berkeley Laboratory
}

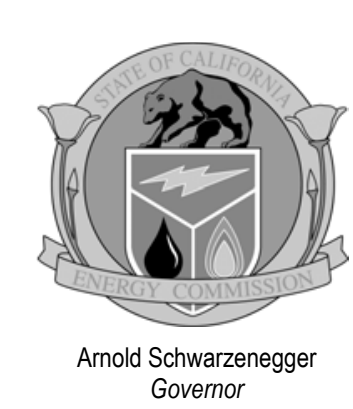

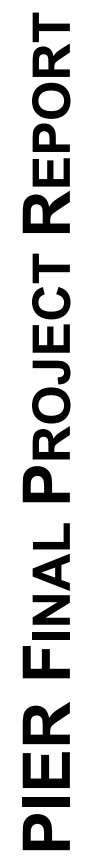




\title{
Development of an Implementation Plan for Atmospheric Carbon Monitoring in California
}

\author{
Principal Investigator:
}

Marc L. Fischer, Staff Scientist

E.O. Lawrence Berkeley National Laboratory

Berkeley, California

Prepared for:

The California Energy Commission

PIER-Environmental Area Exploratory Grant Program

Kelly Birkinshaw, PIER-EA Program Area Lead

Gina Barkalow, Environmental Exploratory Grant Program Manager

Edward Vine, UCOP CIEE Program Administrator

Contract \#500-02-004 - MRA \#03-22 (\$75,000)

Publication Number: XXX

Draft: $11 / 04 / 2004$ 


\section{Legal Notice}

This report was prepared as a result of work sponsored by the California Energy Commission (Energy Commission). It does not necessarily represent the views of the Energy Commission, its employees, or the State of California. The Energy Commission, the State of California, and its employees, contractors, and subcontractors make no warranty, express or implied, and assume no legal liability for the information in this report, nor does any party represent that the use of this information will not infringe upon privately owned rights. This report has not been approved or disapproved by the Energy Commission nor has the Energy Commission passed upon the accuracy or adequacy of this information in this report.

\section{Acknowledgements}

This report was written by Dr. Marc L. Fischer (Principal Investigator), Dr. William J. Riley, and Dr. Shaheen Tonse (Staff Scientists, Berkeley Laboratory). We thank Mark Janssen at LADCO for a gridded version of the US EPA National Emissions Inventory. We acknowledge useful conversations with Dennis Baldocchi, Joe Berry, Robert Bornstein, Nancy Brown, Robert Harley, Karina Garbesi, Allen Goldstein, John Lin, Pieter Tans, and Margaret Torn. The quality of this report we significantly improved by the valuable comments provided by Guido Franco, Edward Vine, and three anonymous reviewers. 


\begin{abstract}
This report describes the design of atmospheric $\mathrm{CO}_{2}$ concentration measurements that, in combination with other measurements and models, would be used to quantify regionally distributed $\mathrm{CO}_{2}$ exchanges from California's terrestrial ecosystems and $\mathrm{CO}_{2}$ emissions from fossil fuel combustion. Using models of net ecosystem $\mathrm{CO}_{2}$ exchange (NEE), fossil fuel $\mathrm{CO}_{2}$ emissions, and regional meteorology, we predict $\mathrm{CO}_{2}$ concentration "signals" in the atmosphere. The predictions of NEE exhibit spatial and temporal variations that are controlled by land cover and climate. Fossil fuel $\mathrm{CO}_{2}$ emissions from metropolitan areas are the strongest localized sources of $\mathrm{CO}_{2}$ while weaker but spatially extensive fossil emissions are present throughout the Central Valley. We subdivide the $\mathrm{CO}_{2}$ sources into four components: NEE inside and outside $\mathrm{CA}$, and fossil fuel $\mathrm{CO}_{2}$ inside and outside $\mathrm{CA}$. Maps of predicted atmospheric $\mathrm{CO}_{2}$ concentration signals from these four sources largely mirror the instantaneous emissions near strong sources but plumes of $\mathrm{CO}_{2}$ enriched or depleted air are predicted to advect far from their sources. We then identify a baseline set of observing stations from existing and possible future sites that could be used to characterize in-state and out-of-state ecosystem and fossil fuel contributions to atmospheric $\mathrm{CO}_{2}$ concentrations. For each of the stations we calculate mean midday concentration signals with standard deviation for each month and source. We also calculate the covariance of the signal due to NEE inside CA with each of the other signals to quantify how much of the signal from NEE inside CA might be readily separable from the other signals. On the basis of these predictions, we identify new observing stations and a measurement protocol that, in combination with existing stations, would provide data to estimate NEE within CA. Although beyond the scope of this project, future work should estimate the uncertainties in estimating California's NEE that would be obtained using atmospheric concentration data from the stations identified herein.
\end{abstract}

Keywords: greenhouse gas emissions, atmospheric monitoring, inverse methods, land-surface $\mathrm{CO}_{2}$ modeling 


\section{Preface}

The Public Interest Energy Research (PIER) Program supports public interest energy research and development that will help improve the quality of life in California by bringing environmentally safe, affordable, and reliable energy services and products to the marketplace. The PIER Program, managed by the Energy Commission, annually awards up to $\$ 62$ million to conduct the most promising public interest energy research by partnering with Research, Development, and Demonstration (RD\&D) organizations, including individuals, businesses, utilities, and public or private research institutions. PIER funding efforts are focused on the following six RD\&D program areas:

- Buildings Energy Efficiency End Use

- Industrial/Agricultural/Water End-Use Energy Efficiency

- Renewable Energy

- Environmentally-Preferred Advanced Generation

- Energy-Related Environmental Research

- Energy Systems Integration.

What follows is the draft report for the PIER-EA Exploratory Grant contract, Contract Number \#500-02-004 - MRA \#015-009, conducted by the Lawrence Berkeley National Laboratory. The report is entitled "Development of an Implementation Plan for Atmospheric Carbon Monitoring in California" This project contributes to the Energy-Related Environmental Research program. For more information on the PIER Program, please visit the Energy Commission's web site at http://www.energy.ca.gov/research/index.html or contact the Energy Commission's Publications Unit at 916-654-5200. 


\section{Executive Summary}

\section{The Issue}

Carbon dioxide $\left(\mathrm{CO}_{2}\right)$ is a greenhouse gas $(\mathrm{GHG})$ that is emitted by fossil fuel combustion for electricity production, transportation, industry, and other human uses. Globally, roughly half of the $\mathrm{CO}_{2}$ emitted by fossil fuel combustion remains in the atmosphere, leading to sustained increases in atmospheric $\mathrm{CO}_{2}$ concentrations. In-state electricity generation accounts for about $16 \%$ of California's anthropogenic $\mathrm{CO}_{2}$ emissions. ${ }^{1}$ Because these emissions contribute to human-induced climate change, the California Energy Commission (Energy Commission) has identified the study of $\mathrm{CO}_{2}$ and other GHGs as a priority area for research, with a particular focus on identifying $\mathrm{CO}_{2}$ sources. Future cost and production strategies for electricity generation may be affected by economic and policy responses to global warming. Therefore, it will be important to determine the contribution of fossil fuel combustion and other sources of $\mathrm{CO}_{2}$ exchange to atmospheric $\mathrm{CO}_{2}$ levels.

Currently, the Energy Commission estimates $\mathrm{CO}_{2}$ emissions using accounting data for fossil fuel emissions and a combination of inventory surveys and simple models for net ecosystem exchange $^{2}$ (i.e., the net balance of ecosystem carbon fluxes into and out of the atmosphere, NEE) of $\mathrm{CO}_{2}$. The net ecosystem fluxes occur continuously and uncertainties associated with these fluxes are poorly quantified.

At the national level, the carbon cycle community was posed with the analogous problem of providing defensible estimates of net $\mathrm{CO}_{2}$ (and other $\mathrm{GHG}$ ) exchange. In response, the research community suggested a North American Carbon Program (NACP) to provide a robust approach for reducing the uncertainties in regional $\mathrm{CO}_{2}$ exchange estimates. The NACP is envisioned to combine inventory methods of biosphere carbon stocks and fossil fuel emissions, direct $\mathrm{CO}_{2}$ flux measurements ${ }^{3}$, and measurements of atmospheric $\mathrm{CO}_{2}$ concentrations, all coupled within an inverse analysis ${ }^{4}$ employing ecosystem-atmosphere models of NEE and atmospheric transport.

\footnotetext{
${ }^{1}$ California Energy Commission. November 2001. Inventory of California Greenhouse Gas Emissions and Sinks: 1990-1999. P600-02-001F. Figure ES-8.

${ }^{2} \mathrm{NEE}$ is the net flow of $\mathrm{CO}_{2}$ from terrestrial ecosystems to the atmosphere. For both NEE and fossil fuel $\mathrm{CO}_{2}$ emissions, fluxes are defined so that a positive flux causes an increase in atmospheric $\mathrm{CO}_{2}$ concentrations.

${ }^{3}$ Direct flux measurements quantify $\mathrm{CO}_{2}$ exchange over a limited area using micrometeorological methods. For example, the eddy covariance method employs rapid measurements of vertical wind velocity and $\mathrm{CO}_{2}$ concentration to calculate the net flux of $\mathrm{CO}_{2}$ as average of $\mathrm{CO}_{2}$ concentration weighted by vertical velocity. Equivalently, the flux can be viewed as the net difference in the amount of $\mathrm{CO}_{2}$ carried upward minus downward with the atmospheric eddies.

${ }^{4}$ Mathematical inverse methods estimate the spatial and temporal distribution of surface fluxes that are most consistent with measurements of $\mathrm{CO}_{2}$ concentration by working backward from concentration to flux under the assumption that $\mathrm{CO}_{2}$ concentrations are the result of surface fluxes being transported in the atmosphere by
} 
Measurement of $\mathrm{CO}_{2}$ concentration gradients on regional scales is challenging because the concentration differences generated by NEE are in the range of less than $1 \mathrm{ppm}$ to approximately $20 \mathrm{ppm}$. Sufficiently accurate measurements can be accomplished for signals greater than about $1 \mathrm{ppm}$ from the instrument perspective, as the state of the art in measurement accuracy is approximately $0.2 \mathrm{ppm}$ of $\mathrm{CO}_{2}$. A careful examination of the expected concentration signals from NEE and fossil fuel $\mathrm{CO}_{2}$ emissions is an important first step in assuring that atmospheric methods can be applied successfully to California.

\section{Anticipated Benefits for California}

This work benefits California electricity rate-payers by providing the foundation for a network of atmospheric monitoring sites and trace-gas sampling protocols that will enable researchers to more precisely identify the $\mathrm{CO}_{2}$ contributions from ecosystem processes and fossil fuel combustion to global warming. The resulting tool will enable the quantification and verification of net $\mathrm{CO}_{2}$ emissions, strategies for within-state carbon sequestration, and emissions trading. This project addresses state and national needs for quantification of terrestrial sources and sinks of carbon cycle gases.

\section{Project Objectives}

With the goal of designing a system of atmospheric concentration measurements as part of a larger strategy for monitoring $\mathrm{CO}_{2}$ exchange in California, we identified four objectives:

I. Predict temporal and spatial distributions of NEE and meteorology in the Western US for representative time periods covering the seasonal cycle of NEE.

II. Predict temporal and spatial distributions of fossil fuel $\mathrm{CO}_{2}$ emissions in the Western US.

III. Predict temporal and spatial distributions of $\mathrm{CO}_{2}$ concentration signals due to NEE and fossil fuel $\mathrm{CO}_{2}$ emissions inside and outside California.

IV. Use the atmospheric $\mathrm{CO}_{2}$ concentration signals predicted for existing and potential future monitoring stations to judge the suitability of these stations for quantifying NEE within CA.

meteorology. See for example, Kasibhatla, P. and American Geophysical Union (2000). Inverse methods in global biogeochemical cycles. Washington, DC, American Geophysical Union. 


\section{Key Results}

- The predicted atmospheric $\mathrm{CO}_{2}$ concentration signals from NEE at many locations within $\mathrm{CA}$ are both measurable with existing methods and often comparable or significantly larger than signals from fossil fuel emissions.

- The predicted $\mathrm{CO}_{2}$ concentrations at marine buoys and coastal stations are significantly affected by terrestrial signals and cannot be used to represent global background $\mathrm{CO}_{2}$ concentrations without thoughtful correction.

- A combination of existing terrestrial sites including flux measurement sites and tall communication towers would likely be effective as observation stations for separating $\mathrm{CO}_{2}$ concentration signals from NEE within CA from signals due to fossil fuel emissions and NEE outside CA.

\section{Project recommendations}

$\mathrm{CO}_{2}$ observing stations, sampling frequencies, measurement protocols:

- New terrestrial sites sensitive to California NEE: New terrestrial observation stations should be deployed, likely on existing communications tall towers in California where signals are predominantly influenced by NEE or fossil fuel $\mathrm{CO}_{2}$ emitted within CA.

- Sampling frequency: Air sampling should be conducted continuously in an automated manner to accurately capture the concentration during the well-mixed afternoon period and the diurnal variation. Data should be collected and averaged into approximately 30 minute intervals for further analysis. However, if resources are limited, periodic sampling with National Oceanic and Atmospheric Administration's (NOAA) flask sampling systems ${ }^{5}$ could capture day versus night differences, providing valuable initial data to test the model predictions from this and other studies.

- Measurement protocol: Air sampling and analysis, instrument design, calibration, and analysis should follow established methods to ensure accuracy and minimize systematic errors. Continuous measurements should be checked against measurements with NOAA flask systems. In addition to the $\mathrm{CO}_{2}$ data, standard ancillary meteorological data (e.g., temperature, relative humidity, wind velocity) should also be gathered and recorded.

- Additional stations: Observations are planned for a variety of platforms to monitor background air entering California for carbon cycle and air quality purposes. This will likely include the three planned marine stations planned by NOAA, periodic aircraft profiling planned by NOAA, and sampling from one or more mountain-top stations. It is also expected that existing flux measurement sites will be augmented with accurate and

\footnotetext{
${ }^{5}$ NOAA conducts routine sampling and laboratory analysis of air samples using standardized methods. http://www.cmdl.noaa.gov/ccgg/flask.html
} 
precise $\mathrm{CO}_{2}$ concentration measurements. These data sets should be included in future analyses.

Uncertainty Analysis and Station Optimization

- Future work should expand on the present study to predict the uncertainty that will likely be obtained in estimating the total NEE from inside California from the measured concentration data.

- Each of the major sources of uncertainty (e.g., spatial coverage of stations, background subtraction, and transport error) should be quantified in terms of uncertainty in estimating NEE.

- Future simulations should include several complete annual cycles to sample different weather patterns and to capture inter-annual variations in NEE.

Measurement of additional trace gas species:

- Where possible, carbon monoxide (CO) measurements should be included with $\mathrm{CO}_{2}$ measurements to quantify fossil fuel $\mathrm{CO}_{2}$ emissions. The use of other sources of $\mathrm{CO}$ (and other pollutant) data from the California Air Resources Board (CARB) might play a valuable part in this effort, particularly near urban areas where pollutant concentrations are high enough to be clearly detected with available instruments.

- Because fossil fuel $\mathrm{CO}_{2}$ contains no radiocarbon $\left({ }^{14} \mathrm{C}\right)$, measurements of ${ }^{14} \mathrm{CO}_{2}$ in atmospheric samples can be used to infer the fraction of $\mathrm{CO}_{2}$ due to fossil fuel combustion. Because of the high cost for precision analysis, this technique can probably only be applied with a low sampling frequency.

- The use of ${ }^{222} \mathrm{Rn}$ as a tracer of atmospheric mixing should be explored for use in combination with $\mathrm{CO}_{2}$ measurements to quantify net regional $\mathrm{CO}_{2}$. This technique may be well suited to the problem of CA carbon budgets, because much of the air entering CA is of marine origin and will be depleted in ${ }^{222} \mathrm{Rn}$.

Data Synthesis:

- A crucial aspect of monitoring California's $\mathrm{CO}_{2}$ emissions using the concentration measurements in an inverse or "top-down" approach will be to sensibly incorporate "bottom-up" information (e.g., ecosystem production from forest inventories and crop yields, fossil $\mathrm{CO}_{2}$ emissions from improved inventory methods, eddy covariance $\mathrm{CO}_{2}$ flux data from towers and aircraft flights, and ecosystem models of $\mathrm{CO}_{2}$ exchange). This approach is an emerging area and developments in the North American Carbon Program (NACP) will be valuable to addressing these issues in CA. 


\section{Estimating Non- $\mathrm{CO}_{2} \underline{\mathrm{GHG} \text { emissions: }}$}

- The methods that we have applied here could be used to develop a measurement strategy for non- $\mathrm{CO}_{2} \mathrm{GHGs}$. Because the relative uncertainties for fluxes of non- $\mathrm{CO}_{2} \mathrm{GHGs}$ are considerably larger than for $\mathrm{CO}_{2}$, atmospheric budget and inverse approaches may be particularly effective in significantly reducing those uncertainties if atmospheric observations can be performed. 


\section{Table of Contents}

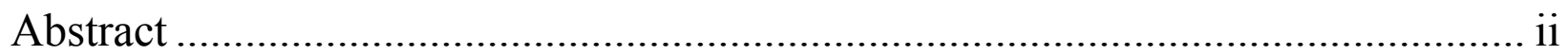

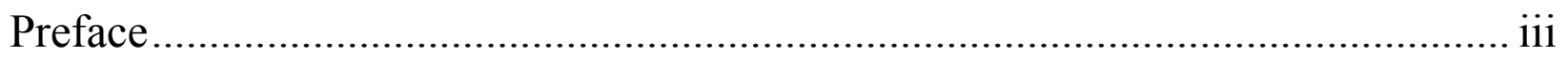

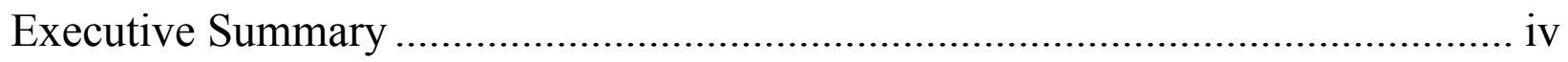

Anticipated Benefits for California................................................................................... v

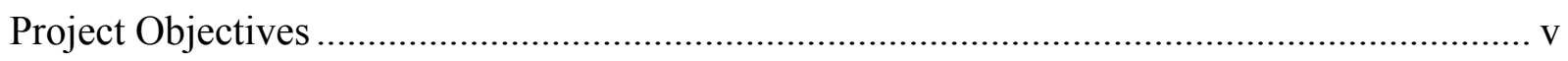

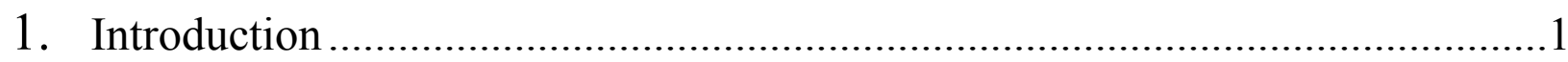

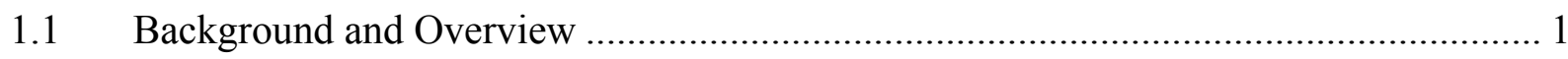

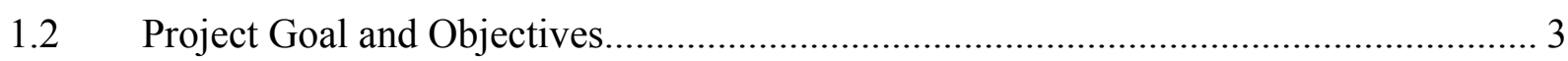

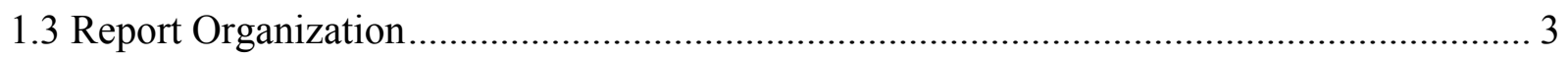

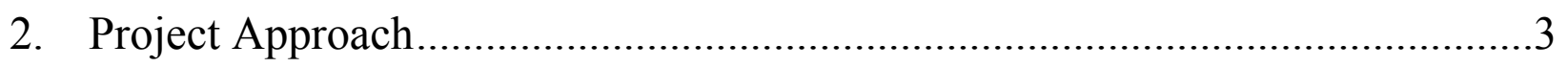

2.1 Prediction of NEE and Meteorology ..................................................................... 3

2.2 Prediction of Fossil Fuel $\mathrm{CO}_{2}$ Emissions .............................................................. 5

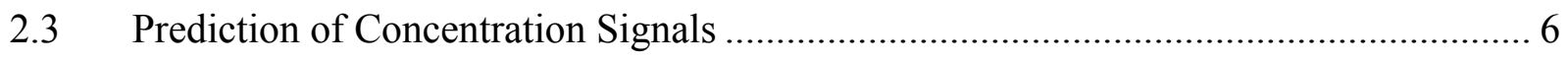

2.4 Identification and Evaluation of Observation Stations ............................................... 7

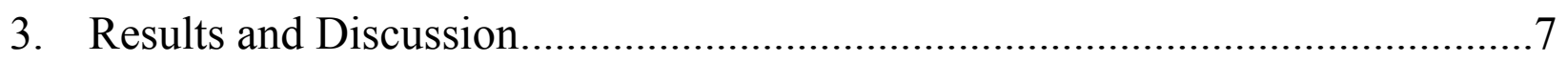

3.1 Spatiotemporal distribution of Net Ecosystem Exchange ……………………............. 7

3.2 Spatiotemporal distribution of fossil fuel $\mathrm{CO}_{2}$ emissions.......................................... 9

3.3 Spatiotemporal distribution of $\mathrm{CO}_{2}$ concentrations in the atmosphere........................ 10

3.4 Identification and Evaluation of Observation Stations ............................................... 13

3.4.1 Existing and Potential Future Stations .............................................................. 13

3.4.2 $\quad \mathrm{CO}_{2}$ concentration signals at monitoring station locations ................................... 14 
3.4.3 How well do concentration signals at monitoring sites allow discrimination of NEE inside CA from other signals?.................................................................................. 15

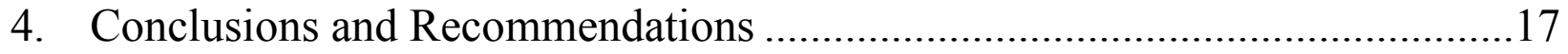

4.1 Observation Stations and Sampling Frequency …………………............................. 17

4.2 Uncertainty Analysis and Site Optimization........................................................... 18

4.3 Additional Trace Gas Species for $\mathrm{CO}_{2}$ Source Attribution ........................................ 19

4.4 Synthesis of Bottom-Up and Top-Down Methods ………………………................. 19

4.5 Potential for Monitoring Non- $\mathrm{CO}_{2}$ GHG Emissions …………………………......... 20

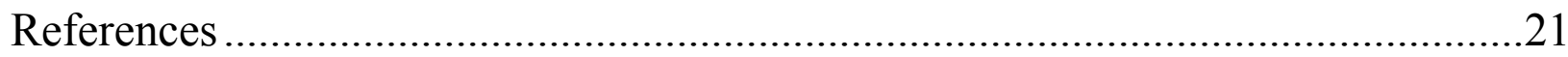

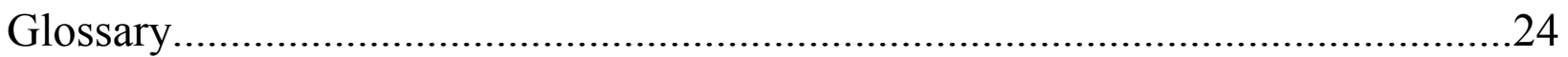

Appendix A. Diurnal and Seasonal Variations in NEE ........................................25

Appendix B. Seasonal Cycle of Mean Midday $\mathrm{CO}_{2}$ Concentration Signals ..........26

Appendix C. Seasonal Cycles of Mean Midday Concentration Signals at

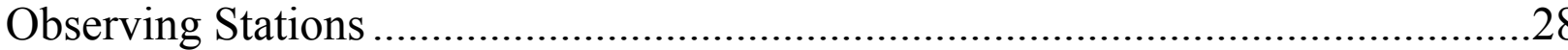




\section{List of Figures}

1 Vegetation distribution used to characterize land cover for the Western US...................5

$2 \quad$ Maps showing the diurnal cycle of predicted net ecosystem exchange............................8

3 Maps showing the diurnal cycle of estimated fossil fuel $\mathrm{CO}_{2}$ emissions ........................9

4 Maps of diurnal variations in surface layer $\mathrm{CO}_{2}$ concentrations from NEE....................10

5 Maps of diurnal variations surface layer $\mathrm{CO}_{2}$ concentrations from fossil fuel $\mathrm{CO}_{2} \ldots \ldots \ldots . .11$

6 Maps of June midday mean surface layer $\mathrm{CO}_{2}$ concentrations......................................12

$7 \quad$ Maps of positions of existing and possible future observations stations ..........................13

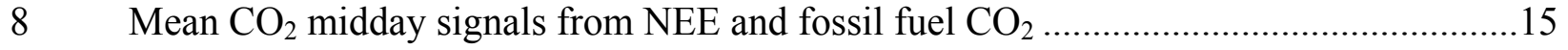

9 Standard deviation of midday signals from in-state NEE and covariance with other

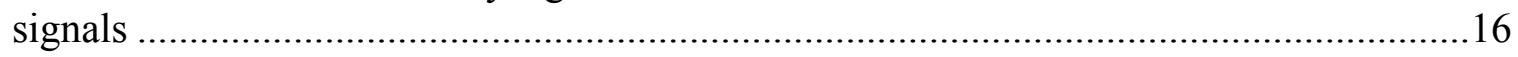

\section{List of Tables}

$1 \quad$ Existing and potential monitoring stations 


\section{Introduction}

\subsection{Background and Overview}

The Intergovernmental Panel on Climate Change (IPCC) concluded that anthropogenic increases in atmospheric GHG concentrations are affecting global climate (IPCC 2001). In California and the Western U.S., recent work indicates that the future quality of environmental services may be compromised by changing climate (Wilkinson et al. 2002; Hayhoe et al. 2004). In response, the Energy Commission has identified quantification of California's net GHG emissions as a research priority. As such, the dominant sources of $\mathrm{CO}_{2}$ emissions from fossil fuel combustion for electricity generation and transportation will be considered in the context of California's total GHG balance. This balance includes contributions from fossil fuel emissions and terrestrial NEE as affected by climate and land-use.

NEE is difficult to quantify on regional scales because (a) the drivers (e.g., climate, land use, and management) are hard to quantify; (b) estimates of gross respiratory and photosynthetic $\mathrm{CO}_{2}$ exchanges are uncertain; and (c) measurements of these exchanges are difficult and expensive to make. Currently, the Energy Commission estimates $\mathrm{CO}_{2}$ emissions using accounting data for fossil fuel emissions and a combination of inventory surveys and empirical models for NEE (Franco 2002). Inventory and simple budget methods are in place to estimate some stocks of ecosystem carbon pools (e.g., aboveground plant biomass, litter, and soil organic carbon) in some locations. However, it is difficult to quantify statewide carbon sources or sinks from changes in stocks because it is expensive to study large areas in sufficient detail and because large uncertainties result from calculating NEE as the difference of large and uncertain stocks. For example, recent work found large inconsistencies between carbon fluxes estimated using US Department of Forestry data in Franco (2002) and fluxes estimated using data provided by the California Department of Forestry (Winrock 2004).

At the national level, the carbon cycle community was posed with the same problem of providing defensible estimates of net $\mathrm{CO}_{2}$ (and other GHG) exchange. In response, the research community suggested the North American Carbon Program (NACP) to provide a robust approach to estimate exchange of $\mathrm{CO}_{2}$ and other carbon cycle GHGs on regional to continental scales (Wofsy et al. 2002) (http://www.esig.ucar.edu/nacp/). Similar efforts are underway in Europe (http://www.bgc-jena.mpg.de/public/carboeur/ ). The NACP is envisioned to combine inventory methods of biosphere carbon stocks and fossil fuel emissions, direct $\mathrm{CO}_{2}$ flux measurements, and atmospheric monitoring of $\mathrm{CO}_{2}$ concentrations, all coupled with inverse analysis employing ecosystem-atmosphere models of NEE and atmospheric transport.

Atmospheric measurements facilitate independent and complimentary approaches to estimating NEE. Micrometeorological methods (e.g., eddy covariance flux) are now employed in networks of ground-based towers to directly measure long-term NEE on plot scales $(\sim 1-10 \mathrm{~km})$

(Baldocchi et al. 2001) and aircraft-based platforms to directly measure short-term NEE on regional scales (10-100 km) (Desjardins et al. 1997). At present, techniques for estimation of seasonal to inter-annual NEE on larger regional scales $(\sim 100-1000 \mathrm{~km})$ are being developed. Some of these include mixing models using a tracer with a known source emission rate (Biraud et al. 2000; Biraud et al. 2002) and atmospheric boundary layer budgets based on assumptions of 
average dynamics in the atmospheric boundary layer (Lloyd et al. 2001; Bakwin et al. 2004; Helliker et al. 2004). As part of NACP, ambitious attempts are now underway to refine inverse techniques originally developed to estimate NEE on global to continental scales (Ciais et al. 1995; Denning et al. 1996; Gurney et al. 2002).

A key feature of the inverse approach is to use NEE predicted by land surface models as an $a$ priori estimate of NEE which is then refined so as to minimize the difference between predicted and observed atmospheric $\mathrm{CO}_{2}$ concentrations to produce an a postiori estimate of NEE. This approach requires a model of atmospheric transport to relate surface fluxes of $\mathrm{CO}_{2}$ to atmospheric concentrations of $\mathrm{CO}_{2}$. The value of this approach is that the uncertainties in the $a$ priori $\mathrm{NEE}$, the transport model, and measured $\mathrm{CO}_{2}$ fluxes and concentrations can be propagated through the analysis to estimate uncertainty in the $a$ postiori NEE estimate. By comparing the $a$ priori and a postiori uncertainties in NEE one can judge whether the atmospheric inversion approach has been effective in improving (reducing uncertainty of) the NEE estimate.

Several future sources of atmospheric data will aid the development of regional estimates. First, the NOAA's Climate Monitoring and Diagnostics Laboratory (NOAA-CMDL) has plans to expand their existing operations (http:/www.cmdl.noaa.gov/publications/annrpt27/) to include additional ground-based sites and vertical profiles of $\mathrm{CO}_{2}$ and other trace gases using aircraft. Second, in 2003, NASA approved the Orbiting Carbon Observatory (OCO). OCO, planned for a 2007 launch, is designed to provide column-integrated measurements of atmospheric $\mathrm{CO}_{2}$ with $1 \mathrm{ppm}$ accuracy on $10 \mathrm{~km}$ swaths separated by roughly $100 \mathrm{~km}$ on a 16 day repeat cycle (Crisp et al. 2004). The global coverage and temporal resolution afforded by OCO will be unique, although the coverage will be sparse at regional scales and the column-integrated signals are significantly smaller than those obtained from surface stations (Olsen et al. 2004). Hence, despite these advances, no current plans include atmospheric $\mathrm{CO}_{2}$ concentration measurements specifically designed to enable accurate estimation of California's net $\mathrm{CO}_{2}$ exchange.

Measurement of $\mathrm{CO}_{2}$ concentration gradients on regional scales is challenging because the spatial gradients are small. In a simplification that aids discussion, the difference in atmospheric concentration $\Delta \mathrm{CO}_{2}(\mathrm{ppm})$ between two towers can be expressed in terms of the average surface rate of net exchange $<\mathrm{NEE}>\left(\mu \mathrm{mol} \mathrm{m} \mathrm{m}^{-2}\right)$ as

$$
\Delta \mathrm{CO}_{2}(\mathrm{ppm})=<\mathrm{NEE}>L /(\rho u h),
$$

where $\mathrm{L}(\mathrm{km})$ is the tower separation $(\mathrm{km}), \rho$ is the molar density of air $\left(\sim 40 \mathrm{~mol} \mathrm{~m}{ }^{-3}\right), \mathrm{u}^{\left.-\mathrm{m} \mathrm{s}^{-1}\right)}$ is the mean wind speed, and $\mathrm{h}$ is the height of the mixing layer $(\mathrm{km})$. For example, $\Delta \mathrm{CO}_{2} /<\mathrm{NEE}>\sim 1 \mathrm{ppm} /\left(\mu \mathrm{mol} \mathrm{m} \mathrm{s}^{-2}\right)$ for a tower separation, $\mathrm{L}=200 \mathrm{~km}$, mean wind, $\mathrm{u}=5 \mathrm{~m}$ $\mathrm{s}^{-1}$, and mixed layer height, $\mathrm{h}=1 \mathrm{~km}$. We note that for a tower separation, $\mathrm{L}=200 \mathrm{~km}$, an air parcel moving over the landscape at $5 \mathrm{~m} \mathrm{~s}^{-1}$ has a transit time between towers of $12 \mathrm{hr}$ or $1 / 2$ day. Since the average uptake over a daytime period is likely to be only -1 to $-10 \mu \mathrm{mol} \mathrm{m} \mathrm{m}^{-2} \mathrm{~s}^{-1}$, the differences in $\mathrm{CO}_{2}$ concentration are 1 to $10 \mathrm{ppm}$. Measuring the $1 \mathrm{ppm}$ to $10 \%$ precision requires relative instrument accuracy of $0.1 \mathrm{ppm}$. This accuracy can be accomplished from the instrument perspective, as the state of the art in measurement accuracy is approximately 0.1-0.2 ppm (Bakwin et al. 1998). High accuracy is necessary because an average annual flux of just 0.1 $\mu \mathrm{mol} \mathrm{m} \mathrm{s}^{-1}$ is equivalent to a change of $0.38 \mathrm{tC} \mathrm{ha}^{-1} \mathrm{yr}^{-1}$. Hence, a careful examination of the 
expected signal levels is an important first step in determining whether inverse methods could be successfully applied to California.

\subsection{Project Goal and Objectives}

The goal of this project is to design a set of atmospheric concentration measurements as part of a larger strategy for monitoring $\mathrm{CO}_{2}$ exchange in California. We identified four objectives to meet this goal:

- Predict temporal and spatial distributions of NEE and meteorology in the Western US for representative time periods covering the seasonal cycle of NEE.

- Predict temporal and spatial distributions of fossil fuel $\mathrm{CO}_{2}$ emissions in the Western US.

- Predict temporal and spatial distributions of $\mathrm{CO}_{2}$ concentration signals due to NEE and fossil fuel $\mathrm{CO}_{2}$ emissions inside and outside California.

- Use predicted atmospheric $\mathrm{CO}_{2}$ concentration signals to identify existing and potential future monitoring stations for suitability in characterizing and separating NEE within CA from other sources.

\subsection{Report Organization}

Section 2 of this report describes our approach. Section 3 describes our results, including spatiotemporal NEE distributions (Section 3.1); spatiotemporal fossil fuel $\mathrm{CO}_{2}$ emission distributions (Section 3.2); spatiotemporal distributions of atmospheric $\mathrm{CO}_{2}$ concentrations (Section 3.3); and identification and evaluation of observing stations (Section 3.4). Section 4 presents conclusions and recommendations on how the Energy Commission can use the project results to choose stations and measurement protocols to provide the most effective augmentation of other existing and planned atmospheric monitoring efforts.

\section{Project Approach}

This section describes the methods used to address each of the objectives described above.

\subsection{Prediction of NEE and Meteorology}

We predict NEE and regional meteorology using a modeling framework (MM5-LSM1) that includes a coupled version of MM5 (Grell et al. 1995) and LSM1 (Bonan 1996). The coupled model was chosen because it provides consistent predictions of NEE and surface energy fluxes (latent and sensible heat) that drive atmospheric mixing. In this section, we describe the coupled model and how it was employed for this work.

MM5 is a mesoscale meteorological model that is used for forecasting regional scale weather and for studying atmospheric dynamics and pollutant dispersion (for a partial list of papers see: http://www.mmm.ucar.edu/mm5/Publications/mm5-papers.html). The model can be run with 
nested grids so that large-scale atmospheric features can be captured as well as impacts of fine scale topography and surface fluxes. LSM1 is a land-surface model that simulates $\mathrm{CO}_{2}, \mathrm{H}_{2} \mathrm{O}$, and energy fluxes between ecosystems and the atmosphere. Twenty-eight land cover types are simulated in the model, each with a specified seasonality for leaf area and parameters controlling soil $\mathrm{CO}_{2}$ flux to the atmosphere. Photosynthesis and ecosystem respiration are calculated at each time step using the land cover information and calculated meteorology in each pixel. LSM1 has been tested in a range of ecosystems at the site level (e.g., (Bonan 1995; Bonan et al. 1997; Riley et al. 2003)). The integration of LSM1 with MM5 was accomplished via the established interface for the OSULSM, with changes in the interface to account for partitioning shortwave radiation between diffuse and direct components (Chen et al. 2001). Previous work has shown that the coupled model's predictions of energy fluxes, near-surface air temperatures, and soil moisture and temperature compared favorably to data collected during a previous field campaign (Betts et al. 1998; Cooley et al. 2004).

We performed four simulations covering the first 15 days of March, June, September, and December of 2003. Although a full year was not simulated due to computational constraints, these periods represent a realistic range of meteorological conditions and ecosystem $\mathrm{CO}_{2}$ exchanges over the year. The model was run with two nested grids with horizontal resolutions of 60 over the entire US, and $20 \mathrm{~km}$ over the modeling shown in Figure 1. The vertical resolution in both grids was 18 logarithmically spaced vertical layers between the surface and $20 \mathrm{~km}$ altitude. The following physics packages were used in the simulations: Grell convective scheme, simple ice microphysics, MRF ABL scheme, and the CCM2 radiation package (http://www.mmm.ucar.edu/mm5). We used the standard initialization procedure for MM5v3.5, which applies first-guess and boundary condition fields interpolated from the National Center for Environmental Prediction (NCEP, http://www.ncep.noaa.gov/ ) reanalysis data (Kalnay et al. 1996; Kistler et al. 2001) to the outer computational grid.

To improve the accuracy of the seasonal cycles of carbon exchange across the different ecosystem types, we compared the predicted NEE with results of eddy covariance flux measurements made in the Western US and available through the FLUXNET data archive (http://daacl.esd.ornl.gov/FLUXNET/) and archival literature (Goldstein et al. 2000; Baldocchi et al. 2001; Falge et al. 2002; Law et al. 2002). Because there are relatively few sites for flux measurements compared to the large number of ecosystem types present in the Western U.S., we aggregated the land cover types present in LSM1 into a subset of seven cover types shown in Figure 1. We then calculated the mean NEE for each cover type using the results of our model runs, with the exception of the desert and urban cover types which produced zero NEE in the model. In the cases where the calculated mean NEE is significantly different from the annual mean flux reported for that cover type, we scaled the daytime and nighttime exchange separately by constant factors for each of the four seasons, so that the daytime and nighttime NEE matched the diurnal cycle from the measurements and the annual mean NEE matched the FLUXNET estimates. Our approach is similar to previous work where the prediction of photosynthesis is assumed to be correct but soil respiration of $\mathrm{CO}_{2}$ is scaled by a constant factor in each pixel to produce zero net annual $\mathrm{CO}_{2}$ exchange (Denning et al. 1996). Our method differs from that approach in that we used field measurements to determine the mean annual carbon balance in a given cover type and did not require that individual pixels were in carbon balance. We believe this is appropriate because many California ecosystems are managed to accomplish a net 
removal of $\mathrm{CO}_{2}$ from the atmosphere (e.g., timber forestry and crop agriculture). In our approach we calculated the annual mean NEE and also the mean NEE for daytime and nighttime in each season from the measurements. If the model predictions of mean annual NEE averaged over a given cover type was significantly different from the mean calculated from field measurements then we scaled NEE in all pixels of that cover type by a constant factor so that both the annual mean and the mean daytime and nighttime NEE matched the field measurements.

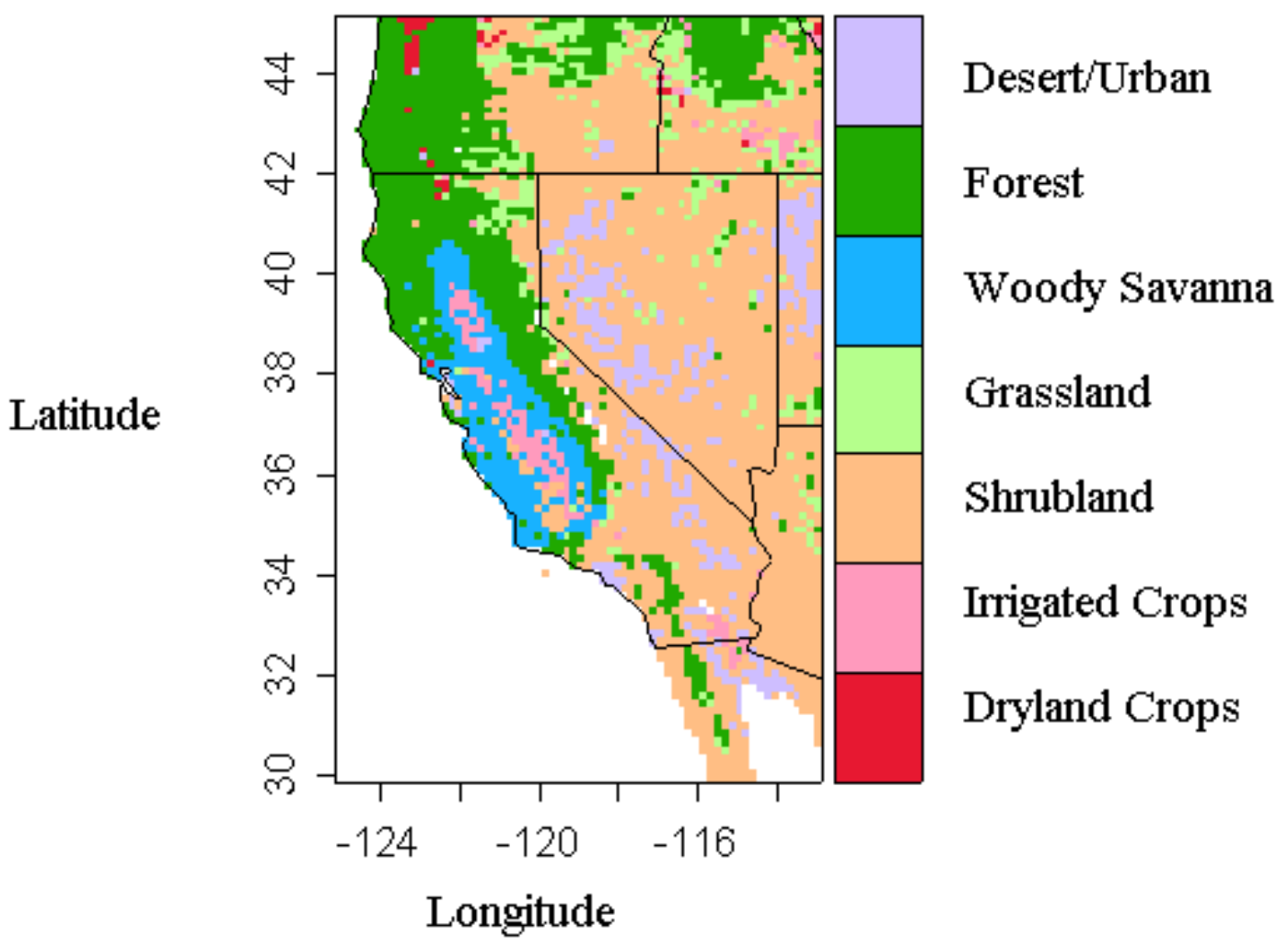

Figure 1. Vegetation distribution used to characterize land cover in the Western US for the simulations described in this report. The pixel size is $20 \mathrm{~km}$ on a side.

\subsection{Prediction of Fossil Fuel $\mathrm{CO}_{2}$ Emissions}

We predicted the spatial and temporal distributions of $\mathrm{CO}_{2}$ from fossil fuel emissions in the Western US by scaling estimated emissions of other combustion related pollutants (e.g., CO, and $\mathrm{NO}_{\mathrm{x}}$ ) that have been shown to correlate with atmospheric $\mathrm{CO}_{2}$ concentration (Potosnak et al. 1999; Dillon et al. 2002; Gerbig et al. 2003; Lamarque et al. 2003). We used CO data reported in the US Environmental Protection Agency's (EPA) National Emission Inventory (NEI) of criteria 
pollutants (EPA 2001). We obtained the NEI database from the Lake Michigan Air District Consortium (LADCO), on a grid with $36 \mathrm{~km}$ resolution for the continental US. The database contained hourly emissions for weekdays, Saturdays, and Sundays of each month in 1999. We extracted the $\mathrm{CO}$ data from the NEI and interpolated it to produce maps at $20 \mathrm{~km}$ resolution. Fossil fuel $\mathrm{CO}_{2}$ emissions were calculated by multiplying $\mathrm{CO}$ emissions by a constant factor of 23.3, so that the annual sum of surface $\mathrm{CO}_{2}$ emissions matched the Energy Commission's estimate of California $\mathrm{CO}_{2}$ emissions in 1999 (363 $\mathrm{Mt} \mathrm{CO}_{2}$ minus approximately $17 \mathrm{Mt} \mathrm{CO}_{2}$ for bunker and aviation fuel combustion) (Franco 2002). This scaling factor is reasonably consistent with previous work on atmospheric $\mathrm{CO}_{2}: \mathrm{CO}$ ratios attributed to signals from fossil fuel combustion (Potosnak et al. 1999).

This method provides a high-resolution picture of fossil fuel $\mathrm{CO}_{2}$ that is sufficient for this planning exercise. However, before using this type of information in an inverse analysis, refinements in the modeling should address the following issues. First, although the fossil $\mathrm{CO}_{2}$ emission maps likely capture the dominant spatial and temporal features of the $\mathrm{CO}_{2}$ emissions, they will contain regions and periods for which the $\mathrm{CO}_{2}: \mathrm{CO}$ ratio varies (e.g., high $\mathrm{CO}$ from biomass burning or low $\mathrm{CO}$ from natural gas fired electricity production). A superior approach would be to use the information on fuel use underlying pollutant emissions to estimate $\mathrm{CO}_{2}$ directly. Second, as mentioned above, these fossil fuel $\mathrm{CO}_{2}$ emissions do not contain bunker or aviation $\mathrm{CO}_{2}$ emissions from marine or aircraft transportation. These emissions can be included with some consideration of their spatial distribution in the atmosphere. Third, the predictions should use an emission inventory specific to the year being simulated or be adjusted appropriately.

\subsection{Prediction of Concentration Signals}

We predicted atmospheric $\mathrm{CO}_{2}$ concentrations using the US EPA Community Multiscale Air Quality (CMAQ) model (http://www.epa.gov/asmdnerl/models3/doc/science/science.html). CMAQ was developed and applied for modeling air quality, incorporating the processes of bulk air motion, turbulent diffusion, and thermal and photo-chemistry (EPA 1999; Cohn et al. 2001; Bullock et al. 2002). Spatially and temporally resolved surface emissions were input to the model. Meteorological inputs were taken from the MM5 model predictions that included wind vectors, atmospheric boundary layer $(\mathrm{ABL})$ height $^{6}$, and vertical velocity fluctuations to compute the motion of air parcels.

CMAQ was used to calculate the temporal and spatial propagation of atmospheric $\mathrm{CO}_{2}$ with the only sources and sinks occurring at the land surface as prescribed by the maps of NEE and fossil fuel $\mathrm{CO}_{2}$ emissions. This is valid because $\mathrm{CO}_{2}$ is not generated or lost through chemical reactions in the atmosphere. Initial and boundary conditions for $\mathrm{CO}_{2}$ concentrations were set to a constant value of $370 \mathrm{ppm}$ and signals were calculated with respect to this background. We subdivided NEE and fossil fuel $\mathrm{CO}_{2}$ into in-state and out-of-state components and then calculated the $\mathrm{CO}_{2}$ signals from four sources of surface flux: 1) NEE within CA (NEE.in), 2)

\footnotetext{
${ }^{6}$ The height in the atmosphere to which air is well mixed.
} 
NEE outside CA (NEE.out), 3) fossil fuel $\mathrm{CO}_{2}$ from combustion inside CA (ffCO2.in), and 4) fossil fuel $\mathrm{CO}_{2}$ from combustion outside $\mathrm{CA}$ (ffCO2.out).

\subsection{Identification and Evaluation of Observation Stations}

We identified an initial set of surface observation stations by starting with existing carbon cycle monitoring networks (e.g., NOAA-CMLD; http://www.cmdl.noaa.gov, and the Ameriflux Program http://public.ornl.gov/ameriflux ). However, because of their relatively sparse coverage, we included two categories of other stations. Some of the additional stations were marine buoys planned by NOAA for offshore monitoring. Others were obtained from lists of radio and television transmission towers (http://wireless2.fcc.gov/UlsApp/AsrSearch) similar to the Park Falls Tower in Wisconsin where $\mathrm{CO}_{2}$ measurements have been made previously (Bakwin et al. 1998).

We evaluated the efficacy of these observing stations by examining the time series concentration signals obtained at each station from the four component sources (NEE.in, NEE.out, ffCO2.in, and ffCO2.out). Three criteria were used in the selection process. First, we wanted to identify marine stations that had only small signals from the terrestrial sources. These stations would be used to quantify the $\mathrm{CO}_{2}$ concentration boundary conditions for air entering the region. Second, we wanted to find stations that provided measurable signals from terrestrial sources. We used the time series data to calculate the mean mid-day signals from each component source and over each season. Mid-day $\mathrm{CO}_{2}$ concentration signals were chosen because the mixing height of the atmospheric boundary layer is generally well defined and, although large, can be accurately represented in meteorological models. By comparison, nighttime atmospheric mixing is often poorly defined and represented. Third, we wanted the signals from NEE.in at the stations to be clearly distinguishable from signals due to the other sources. To quantify the degree of similarity between signals, we calculated the covariance between the signal from NEE.in. and the signals from each of the other three sources. If there was little covariance, then signal variations due to NEE.in could be measured and the signals from other sources would add noise but not bias to the measurement.

\section{Results and Discussion}

\subsection{Spatiotemporal distribution of Net Ecosystem Exchange}

Using the coupled MM5-LSM1 simulations, we predicted regional meteorology and NEE for the Western region over the first 15 days of March, June, September, and December. We calculated the average NEE for each cover type over the four periods of the study. Both the mean NEE for forest $\left(-0.66 \mathrm{t} \mathrm{C} \mathrm{ha}^{-1} \mathrm{yr}^{-1}\right)$ and for shrub lands $\left(0.38 \mathrm{t} \mathrm{C} \mathrm{ha}^{-1} \mathrm{yr}^{-1}\right)$ were close to carbon balance, and reasonably consistent with the range of estimates for the annual NEE from the literature (Goldstein et al. 2000; Baldocchi et al. 2001; Falge et al. 2002; Law et al. 2002). The mean NEE of irrigated crops $\left(-10.5 \mathrm{t} \mathrm{C} \mathrm{ha}^{-1} \mathrm{yr}^{-1}\right)$ and dry crops $\left(-5.5 \mathrm{t} \mathrm{C} \mathrm{ha}^{-1} \mathrm{yr}^{-1}\right)$ both showed the large net uptake expected from managed agricultural systems, where nitrogen is applied and crop residues are removed after harvest. The predicted mean NEE of woody savanna $\left(-19.5 \mathrm{t} \mathrm{C} \mathrm{ha}^{-1} \mathrm{yr}^{-1}\right)$ and grassland ( $\left.-6.2 \mathrm{t} \mathrm{C} \mathrm{ha}^{-1} \mathrm{yr}^{-1}\right)$ were sufficiently different from values observed in California oak woodland (pers. comm. D. Baldocchi) and grassland systems (Xu et al. 2004) that adjustments 
were made to reduce net daytime uptake and increase net nighttime release as described in section 2.1. The resulting mean NEE of woody savanna and grassland were both $-0.7 \mathrm{t} \mathrm{C} \mathrm{ha}^{-}$ $\mathrm{yr}^{-1}$.

Predicted NEE exhibits large variations both in time and with cover type. For example, the maps in figure 2 (and figure A1, appendix A) show the diurnal variation in NEE over the course of a day in June. As expected, nighttime NEE is positive, reflecting plant and soil respiration of $\mathrm{CO}_{2}$ to the atmosphere. Daytime NEE is negative for ecosystems that are actively assimilating $\mathrm{CO}_{2}$ from the atmosphere (e.g., forest, woodland, and crop lands), but slightly positive for shrub ecosystems where, on this day, respiration was larger than photosynthesis. The large spatial variations in NEE reflect the varied ecosystems present in California. Similarly, the ecosystems have different seasonality, which generates seasonal NEE patterns (see figure A2 in Appendix A). Capturing these seasonal NEE variations is important in order to accurately predict seasonal variations in atmospheric $\mathrm{CO}_{2}$ concentrations.
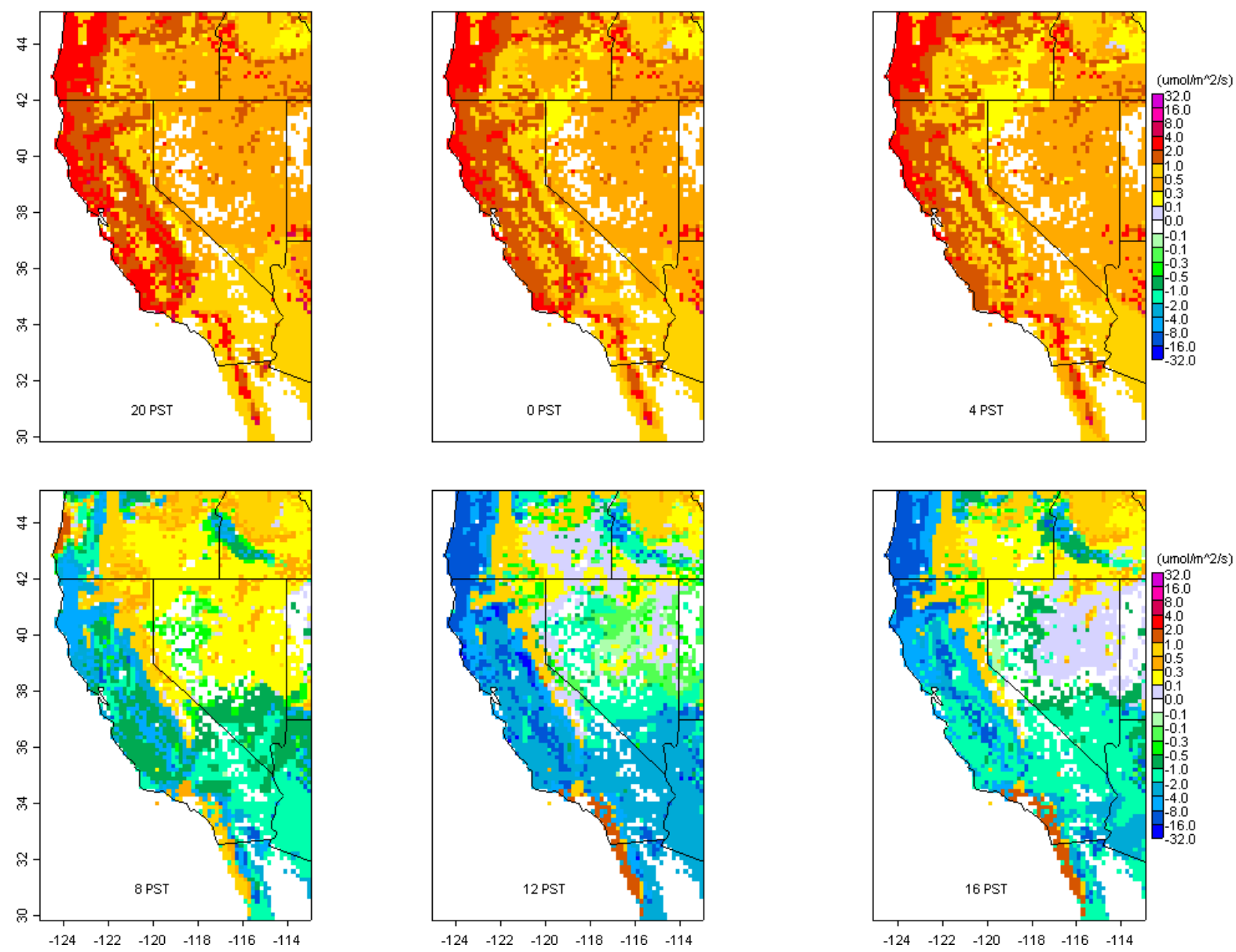

Figure 2. Maps showing the diurnal cycle of predicted net ecosystem exchange, NEE $\left(\mu \mathrm{mol} \mathrm{CO}_{2}\right.$ $\mathrm{m}^{-2} \mathrm{~s}^{-1}$ ), for a day in June. Horizontal and vertical axes are longitude and latitude respectively. Upper panels show positive fluxes to the atmosphere dominate at night due to respiration. Lower 
panels show negative fluxes to the atmosphere dominate during the day when photosynthesis removes $\mathrm{CO}_{2}$ from the atmosphere. Note: NEE is shown with a logarithmic scale.

\subsection{Spatiotemporal distribution of fossil fuel $\mathrm{CO}_{2}$ emissions}

A representative diurnal cycle of $\mathrm{CO}_{2}$ emissions from fossil fuel combustion in the Western US is shown in Figure 3 for a weekday in June. As expected, fossil fuel $\mathrm{CO}_{2}$ emissions were strong in large urban centers (larger than any positive ecosystem fluxes), but were spatially localized. Away from urban centers, emissions remained significant only along suburban transportation corridors. Emissions from aircraft and ship traffic were not included, but represent a small fraction of estimated $\mathrm{CO}_{2}$ emissions from California. The temporal variations in fossil fuel $\mathrm{CO}_{2}$ fluxes were much smaller than temporal variations in signals from NEE because ecosystems have distinct diurnal and seasonal cycles of net uptake and release. Given that the temporal variations in $\mathrm{CO}_{2}$ concentration signals from fossil fuel $\mathrm{CO}_{2}$ are smaller than the variations from NEE we hypothesize that fossil fuel signals could be predicted and subtracted from measured signals to yield the signal from NEE. This hypothesis should be investigated in future work.
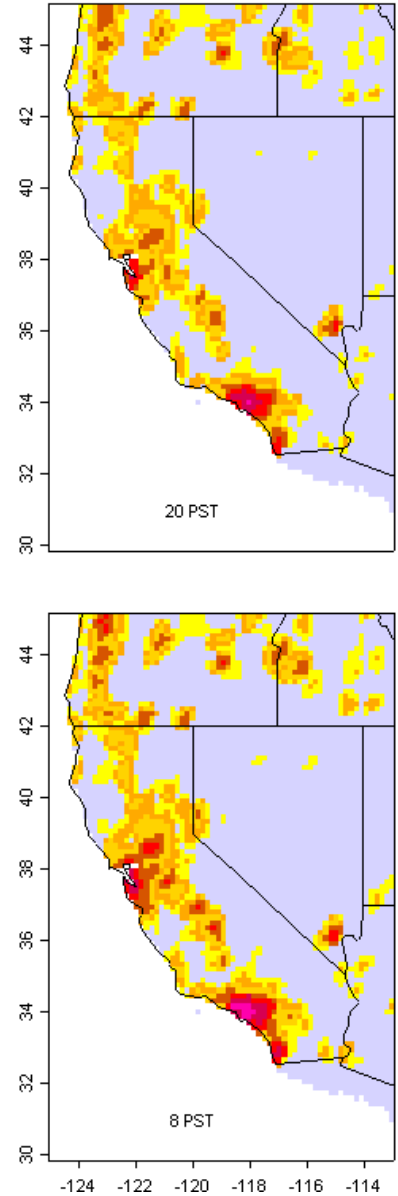
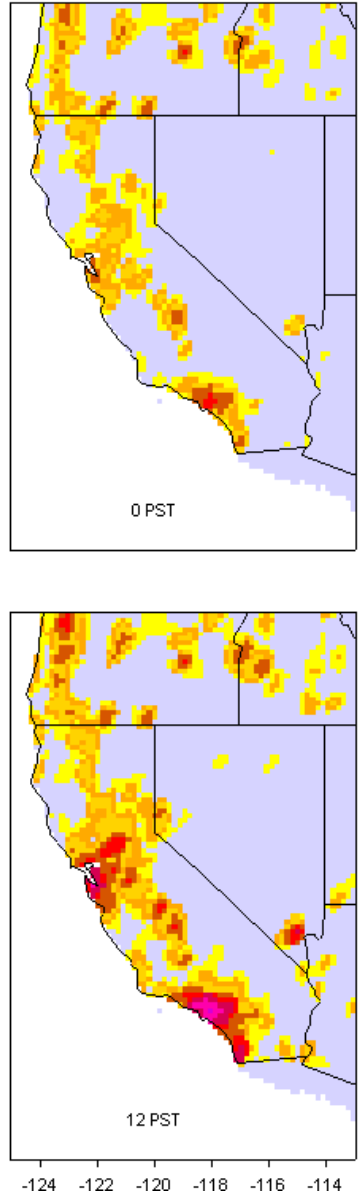
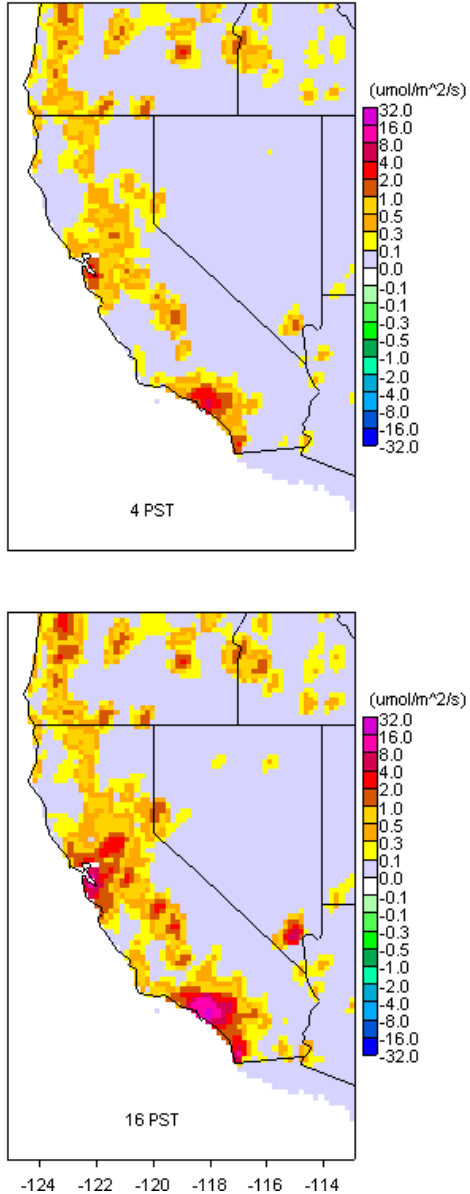
Figure 3. Maps showing the diurnal cycle of estimated fossil fuel $\mathrm{CO}_{2}$ emissions for the Western US for a weekday in June. Panel layout, axes, and logarithmic scale for units are the same as in Figure 2.

\subsection{Spatiotemporal distribution of $\mathrm{CO}_{2}$ concentrations in the atmosphere}

Atmospheric $\mathrm{CO}_{2}$ concentrations were predicted for the four simulation periods using predicted $\mathrm{NEE}$, fossil fuel $\mathrm{CO}_{2}$ emissions, and meteorology described above. All $\mathrm{CO}_{2}$ concentrations are reported as deviations from the constant boundary condition applied at the edge of the simulation domain. Figure 4 shows the diurnal cycle in $\mathrm{CO}_{2}$ concentration signals from NEE in the lowest $(0-100 \mathrm{~m})$ model layer of the atmosphere for the day shown in Figure 2. In areas with strong surface uptake, concentrations were reduced below the background, while in areas with strong sources they increased above the background. Air parcels containing significant $\mathrm{CO}_{2}$ concentration signals were predicted to advect to marine locations up to $300 \mathrm{~km}$ west of the coast, consistent with the results of another study (Riley et al. 2004). This suggests that attempts to use the data from marine and coastal stations to provide boundary condition information on the air entering California will require correction for terrestrial influence. From these maps we can also conclude that the spatial differences in $\mathrm{CO}_{2}$ signals across $\mathrm{CA}$ are large enough to be clearly measured with available instrumentation.

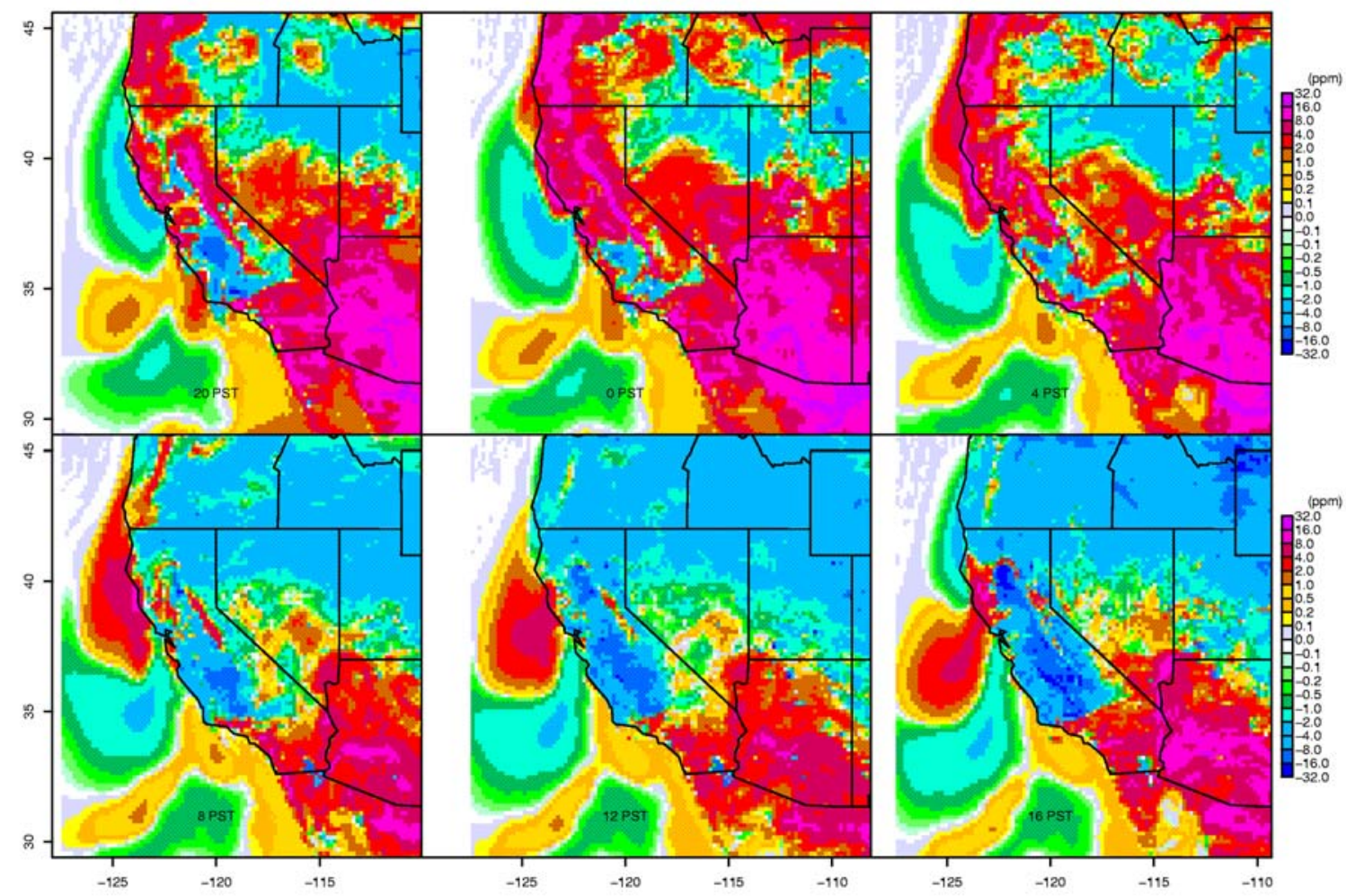

Figure 4. Maps showing diurnal variation in surface layer $\mathrm{CO}_{2}$ concentrations resulting from NEE for the day shown in Fig 2. The upper (lower) three panels correspond to nighttime 
(daytime) periods. Horizontal and vertical axes are longitude and latitude respectively. Note that $\mathrm{CO}_{2}$ concentration contours are logarithmically scaled. The spatial variations in $\mathrm{CO}_{2}$ concentration are large enough to be clearly detected with available instrumentation.

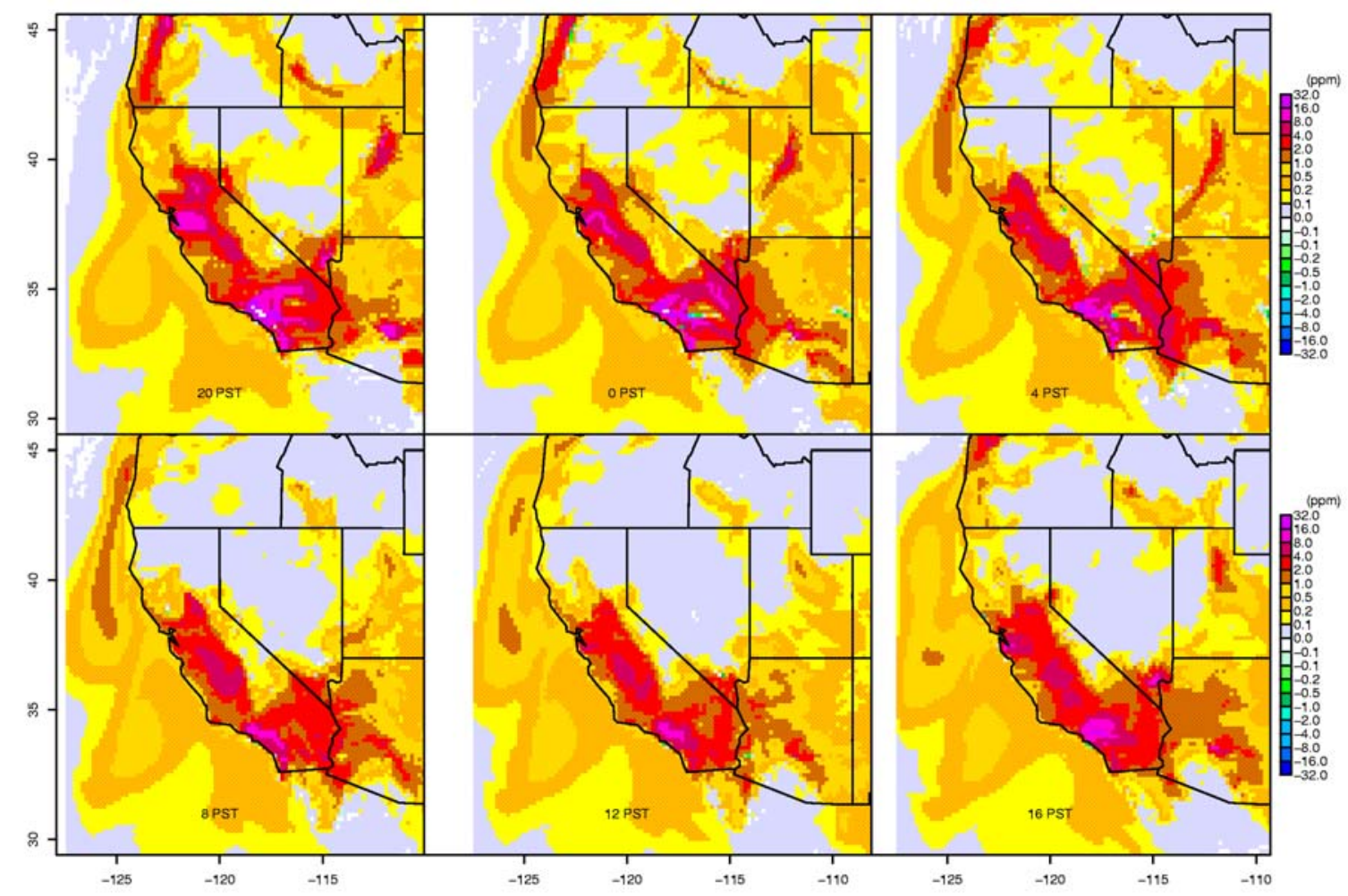

Figure 5. Maps of diurnal variation in surface layer $\mathrm{CO}_{2}$ concentrations resulting from fossil fuel $\mathrm{CO}_{2}$ emission for June time period as in Figure 4. Panel layout, axes, and logarithmic scale for units are the same as in Figure 4.

Figure 5 shows the diurnal cycle in $\mathrm{CO}_{2}$ concentrations resulting from fossil fuel $\mathrm{CO}_{2}$ emissions for the same period as Figure 4. In this case, only increases above background are predicted because all fluxes are positive with respect to the atmosphere. As with the emissions map, the most significant increments in $\mathrm{CO}_{2}$ concentration occurred near the urban centers, but significant plumes of $\mathrm{CO}_{2}$ enriched air were also transported to other locations far from the location of emissions. However, the mean and diurnal variations in fossil $\mathrm{CO}_{2}$ signals were generally smaller than $\mathrm{CO}_{2}$ signals from NEE at most locations away from urban centers. The smaller size and lower variability of fossil $\mathrm{CO}_{2}$ signals suggests that subtracting predicted fossil $\mathrm{CO}_{2}$ signals from future measurements of $\mathrm{CO}_{2}$ concentration may be effective for estimating the signals from NEE at many locations. This increases our confidence that atmospheric observations will enable effective estimation of NEE.

In order to facilitate identification of the most promising locations for observing stations, we calculated the $\mathrm{CO}_{2}$ signals for four components: signals derived from 1) NEE within CA 
(NEE.in), 2) NEE outside CA (NEE.out), 3) fossil fuel $\mathrm{CO}_{2}$ from combustion inside CA (ffCO2.in), and 4) fossil fuel $\mathrm{CO}_{2}$ from outside $\mathrm{CA}$ (ffCO2.out). Figure 6 shows the mean midday surface layer concentration signals for each of the four components in June. The panels of Figure 6 show that the central valley and central coast areas had negative signals from NEE inside $\mathrm{CA}$ and positive signals from fossil fuel $\mathrm{CO}_{2}$ produced inside $\mathrm{CA}$. During this period Southern CA had positive signals from both NEE and fossil fuel $\mathrm{CO}_{2}$. Coastal and marine areas obtained smaller positive signals from plumes transported off the coast. As shown in Appendix $B$, these patterns varied significantly with season. In the case of NEE, the patterns varied because NEE has significant seasonal variations due to ecology and climate. In the case of fossil fuel $\mathrm{CO}_{2}$, the variations are driven mostly by variations in the mean meteorology for the different months.
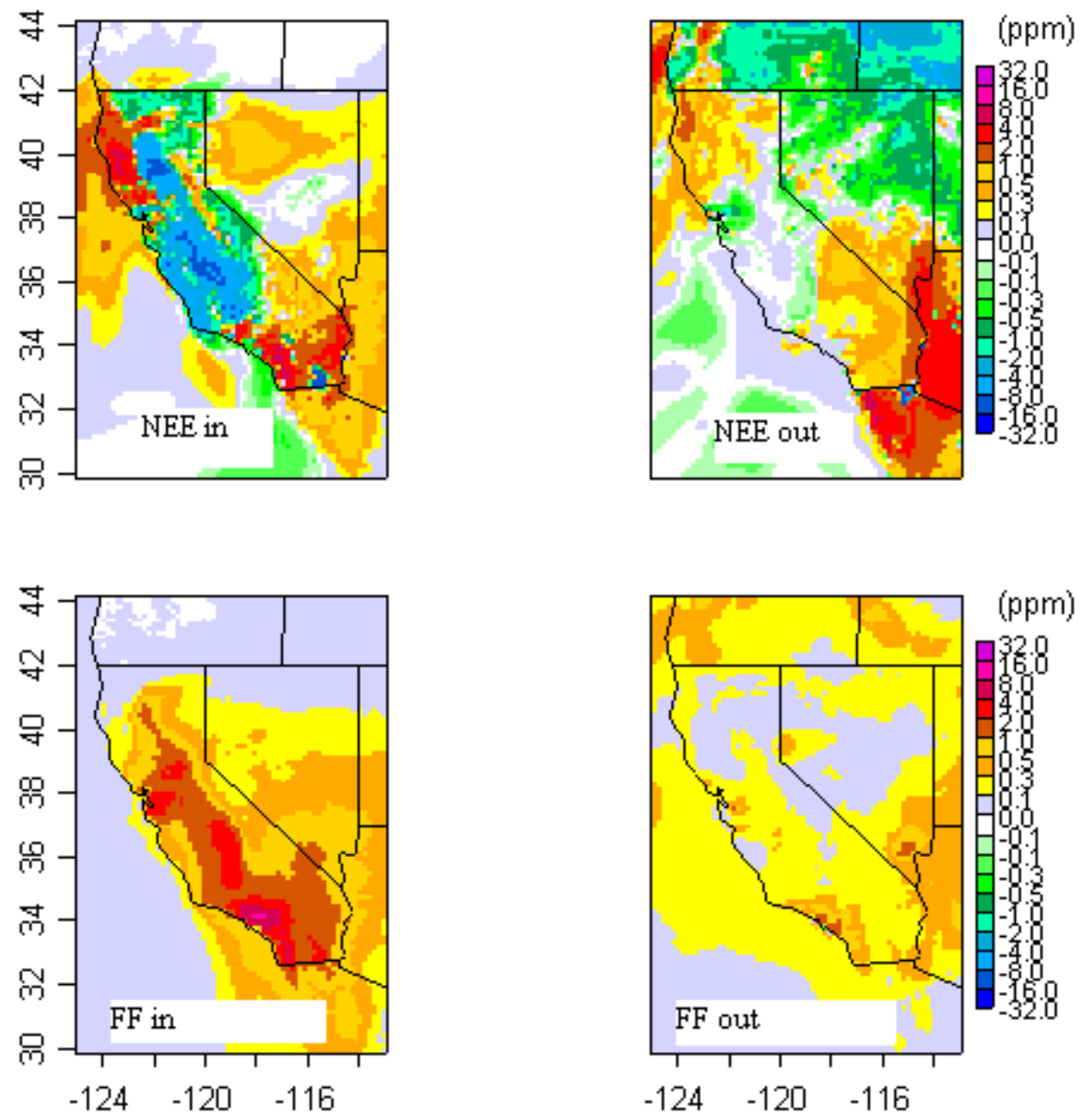

Figure 6. Maps of June midday mean surface layer $\mathrm{CO}_{2}$ concentrations resulting from NEE inside (upper left) and outside (upper right) California, and fossil $\mathrm{CO}_{2}$ emissions inside (lower left) and outside (lower right) California. As with previous figures the horizontal and vertical axes are longitude and latitude respectively. Note that $\mathrm{CO}_{2}$ concentration contours are logarithmically scaled. 


\subsection{Identification and Evaluation of Observation Stations}

\subsubsection{Existing and Potential Future Stations}

A set of existing and potential future monitoring stations is shown in Figure 7 and Table 1. Some of the existing stations are part of the NOAA CMDL measurement and sampling network (see the following report: http://www.cmdl.noaa.gov/publications/annrpt27/), some are independent sites (e.g., Scripps), and others are Ameriflux sites where accurate $\mathrm{CO}_{2}$ measurements could be implemented, and have been at Blodgett Forest (station 13). We note that there are other existing ecological and biogeochemical flux measurement sites in California that could be included in future analysis, but such a compilation was beyond the scope of this study. The marine stations are chosen to sample the atmosphere from relatively pristine locations that provide boundary conditions for air entering the California. The coastal stations sample air in a transition regime. The inland stations sample air that is heavily influenced by terrestrial surface fluxes. We did not include a significant number of sites East of California because the topography of the Sierra poses a serious challenge for modeling atmospheric transport.

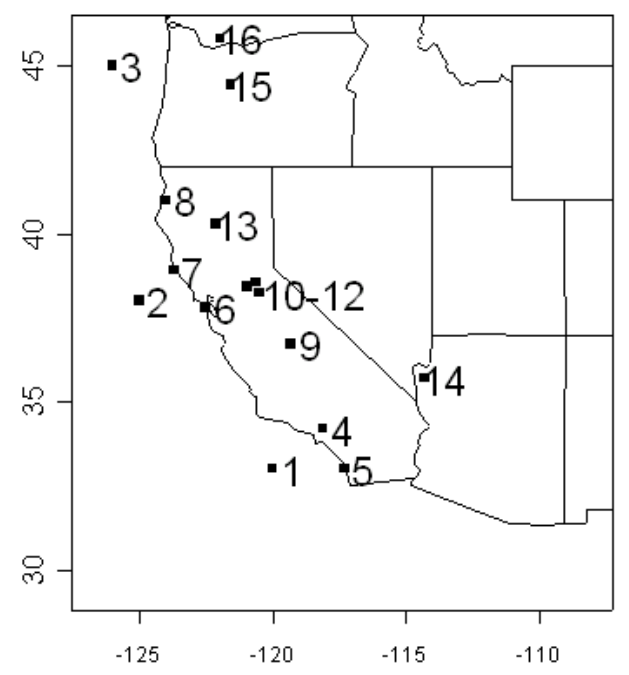

Figure 7. The positions of existing and possible future observations stations examined in this study. The locations range from marine stations that largely sample background air to inland stations that sample air subject to strong terrestrial influence.

Table 1. Existing and potential monitoring stations. For existing sites the name of the research program is listed in parentheses.

\begin{tabular}{|c|l|r|l|r|}
\hline Station & Name & Lat & lon & agl $(\mathrm{m})$ \\
\hline 1 & Buoy & 33.000 & -120.000 & 3 \\
\hline 2 & Buoy & 38.000 & -125.000 & 3 \\
\hline 3 & Buoy & 45.000 & -126.000 & 3 \\
\hline 4 & Tall Tower & 34.200 & -118.100 & 296 \\
\hline
\end{tabular}




\begin{tabular}{|c|l|r|r|r|}
\hline 5 & Scripps Pier (Scripps Inst.) & 33.000 & -117.300 & 10 \\
\hline 6 & Tall Tower & 37.800 & -122.500 & 298 \\
\hline 7 & Point Arena (NOAA) & 38.911 & -123.692 & 10 \\
\hline 8 & Trinidad Head (NOAA) & 41.000 & -124.000 & 10 \\
\hline 9 & Tall Tower & 36.700 & -119.300 & 259 \\
\hline 10 & Tall Tower & 38.240 & -120.502 & 624 \\
\hline 11 & Tonzi Ranch (Ameriflux) & 38.432 & -120.966 & 12 \\
\hline 12 & Blodgett Forest (Ameriflux) & 38.550 & -120.633 & 15 \\
\hline 13 & Tall Tower & 40.300 & -122.100 & 304 \\
\hline 14 & Tall Tower & 35.700 & -114.300 & 396 \\
\hline 15 & Metolious (Ameriflux) & 44.437 & -121.567 & 12 \\
\hline 16 & Wind River (Ameriflux) & 45.821 & -121.951 & 73 \\
\hline
\end{tabular}

\subsection{2 $\mathrm{CO}_{2}$ concentration signals at monitoring station locations}

The time series of concentration signals calculated for each station was extracted from the concentration maps and examined to determine the contributions to the predicted signals from NEE and fossil $\mathrm{CO}_{2}$ emissions inside and outside of California. Figure 8 (and Appendix C) shows the mean midday concentration signal for each station and season. As mentioned above, we separated the stations into categories based on whether their primary influence was oceanic (stations 1-3) and primarily of use for monitoring boundary conditions, coastal (4-8) and influenced by a mixture of marine and interior air, interior (9-13) and strongly influenced by $\mathrm{NEE}$ and fossil $\mathrm{CO}_{2}$, or outside of California (14-16) and of value for monitoring boundary conditions. Within the station groupings, the stations are arranged from South to North.

The general patterns show increasing signals from NEE.in and decreasing signals from ffCO2.in from south to north. This is because Southern CA is quite arid and does not support the high rates of ecosystem carbon exchange that are possible in the comparatively moister conditions found in Northern CA. Other significant features for stations within CA are consistent seasonality (also see Appendix C) with negative NEE.in signals during March, small or positive signals in June near the coast but negative signals inland (from irrigated agriculture and Sierran forests), uniformly positive signals in September when most areas are subject to water stress, and small signals in December when temperatures are lower. Patterns for ffCO2.in and out show less seasonality, largely due to variations in atmospheric transport because fossil emissions did not vary significantly with season.

The signals predicted for the different stations vary by grouping and latitude. Stations 1 and 2 show mean signals of $\sim 1-2 \mathrm{ppm}$ with comparable day-to-day variations, suggesting that their use as background monitoring stations will require incorporating estimated terrestrial signals. We note that this may also be true for station 3; it is near the northwest edge of the modeling domain and signals from terrestrial $\mathrm{CO}_{2}$ exchanges even farther north may influence the signal at station 3. Stations 6-13 showed significant signals from NEE.in, while stations 4, 5, 9,11, and 12 all exhibited large signals from ffCO2.in and could be used to monitor fossil emissions. Stations 14-16 exhibited strong signals from NEE.out and ffCO2.out and would therefore provide information to estimate a combination of those sources. Finally, the signals from the tall towers 
$(4,6,9,10,13,14)$ generally exhibited smaller day-to-day variations as compared with nearby surface stations (Appendix B). This reduced variability occurs because they average over larger areas, a fact that makes them potentially superior for regional inverse studies.

NEE.in
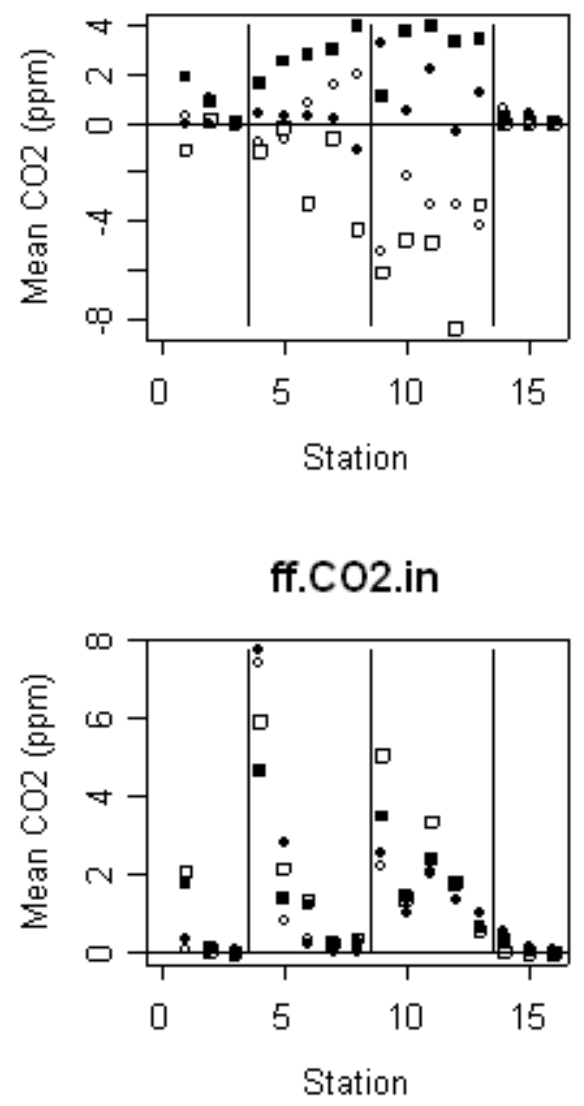

NEE.out
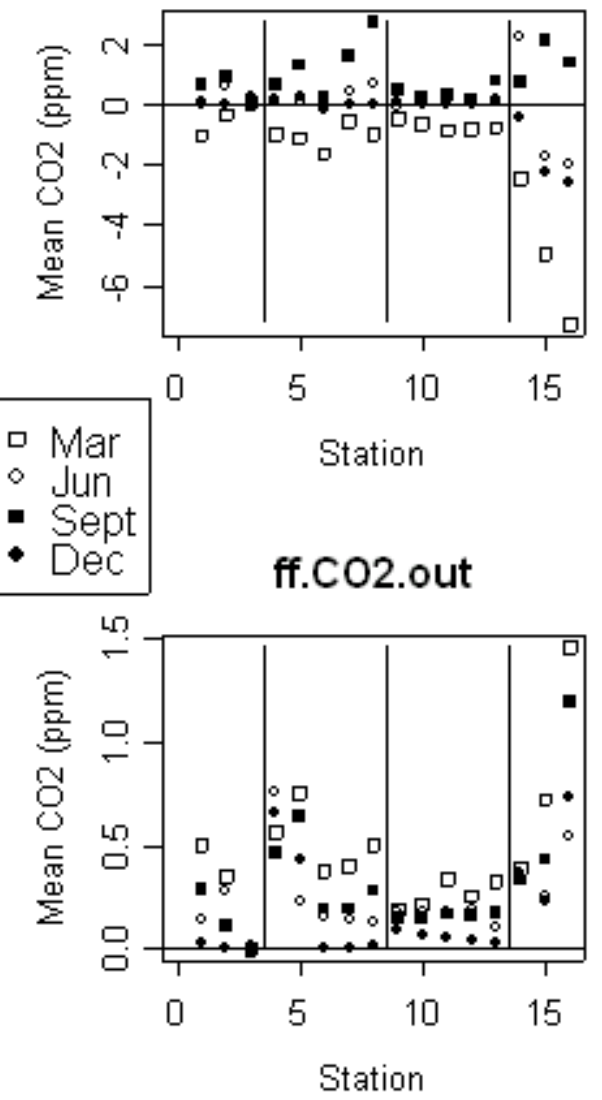

Figure 8. Mean $\mathrm{CO}_{2}$ concentration signals from NEE in and out and fossil fuel $\mathrm{CO}_{2}$ emissions in and out of California for each of the four months examined in this study. Vertical lines separate the stations into four groups in the following order: oceanic, coastal, interior, and interior outside California. $\mathrm{CO}_{2}$ concentrations are deviations from the seasonal background.

\subsubsection{How well do concentration signals at monitoring sites allow discrimination of NEE inside CA from other signals?}

Additional insight into the relative strengths of the observing stations can be obtained by inspecting the covariance between signals from NEE.in and the other signals shown in Figure 9. We normalized the covariance between signals from NEE.in and other signals by the standard deviation in signal from NEE.in. This measure shows the amount of signal variation from the other sources that are correlated with (and could not be distinguished from) variations from 
NEE.in. In most cases, the covarying signals were small compared to the signal variations from NEE.in. This suggests that if the variables governing variation in the signal from NEE.in can be captured in an ecosystem-atmosphere model (e.g., MM5-LSM1), then an inverse model can use the measured signals to estimate NEE.in without interference from the other signals. A subset of stations $(6,7,8,10,12$, and 13) did not exhibit significant signal correlations between NEE.in and ffCO2.in, and only limited correlations with NEE.out and ffCO2.out. Station 12 (Blodgett forest) appeared particularly well suited in this respect, although modeling the transport fields for Blodgett poses a greater challenge (because of the mountainous terrain) than for the Central Valley sites. Based on these results, we conclude that measurements made at a subset of these stations are likely to offer an opportunity to quantify NEE.in without significant interference from other sources.
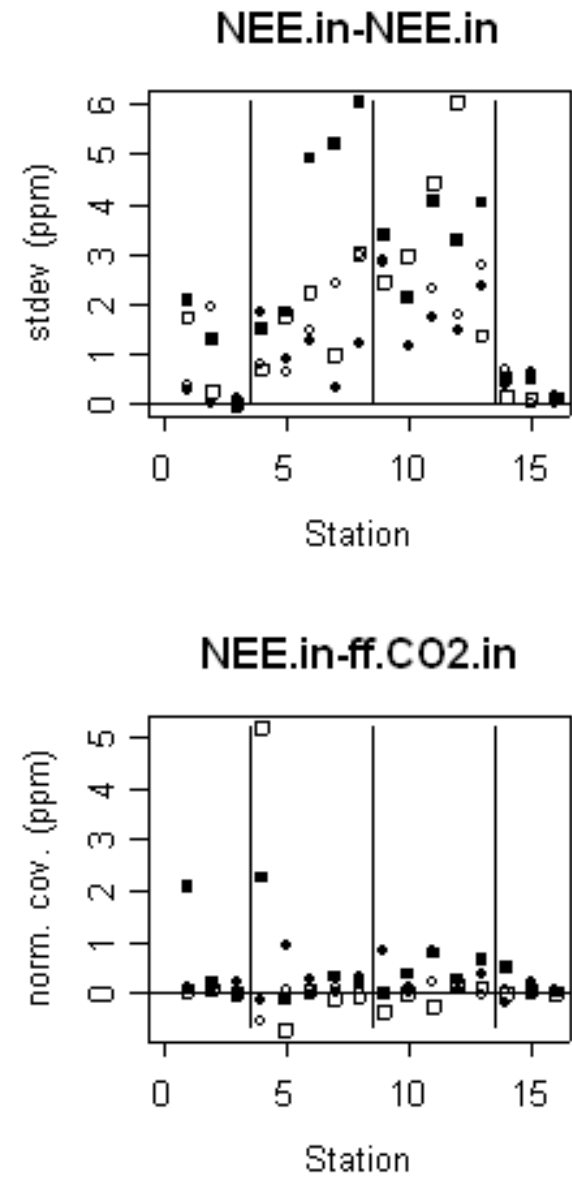
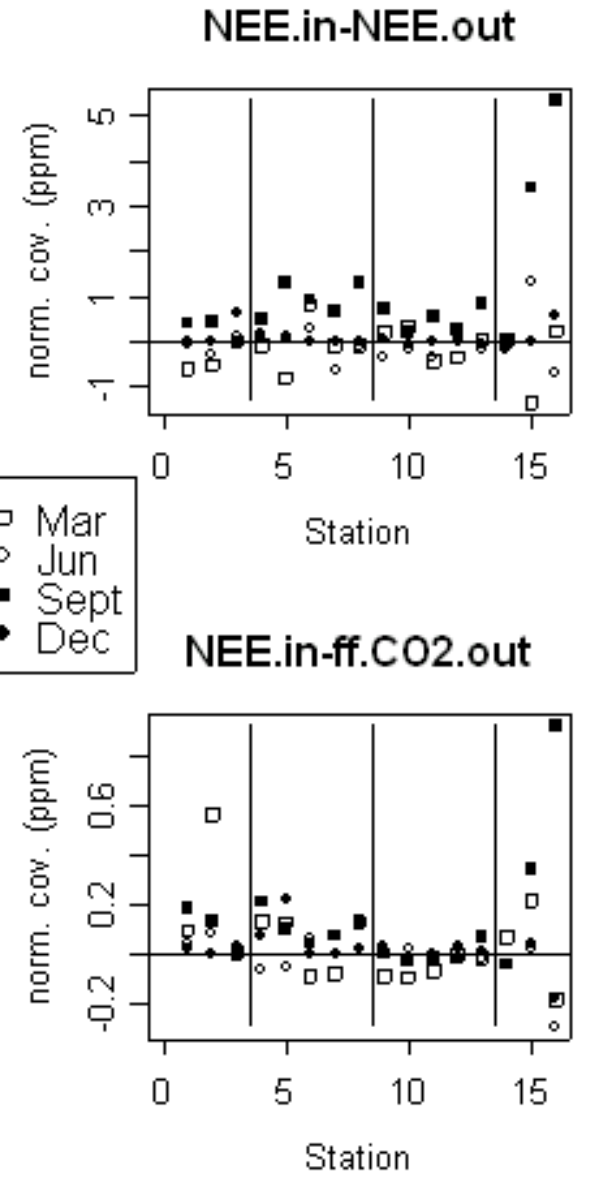

Figure 9. Standard deviation of midday $\mathrm{CO}_{2}$ signals from NEE inside California (top left), showing predicted variation in daytime signals for each season. The normalized covariance of the signal from NEE.in with the other signals is also shown: NEE outside CA (top right), $\mathrm{ffCO}_{2}$ inside $\mathrm{CA}$ (bottom left), and $\mathrm{ffCO}_{2}$ outside $\mathrm{CA}$ (bottom right). In all cases the normalization factor is the standard deviation of NEE.in, yielding the component (or projection) of each signal that is correlated with signal from NEE.in. Several stations show normalized signal covariances 
that are small compared to the standard deviation of the NEE.in signal are hence likely to offer an opportunity to quantify NEE.in without interference from other sources.

\section{Conclusions and Recommendations}

This section provides conclusions and recommendations for 1) a proposed set of initial observation stations, sampling frequencies, and a measurement protocol for $\mathrm{CO}_{2}, 2$ ) analysis of the uncertainties in future inverse model estimates of NEE and refinement of observing stations, 3 ) measurement of additional trace gases that would enhance our ability to estimate $\mathrm{CO}_{2}$ exchange, 4) initiation of a data synthesis effort to couple data from different sources relevant for estimating NEE, and 5) application of atmospheric methods for non- $\mathrm{CO}_{2} \mathrm{GHG}$ emissions.

\subsection{Observation Stations and Sampling Frequency}

The results of this project have shown that there are locations where atmospheric $\mathrm{CO}_{2}$ measurements will help constrain California's NEE. Based on these results, we recommend an initial sampling at a limited number of sites to provide a baseline for future efforts:

- New terrestrial stations: New observing stations should be deployed at existing communications tall towers in California, chosen so that $\mathrm{CO}_{2}$ signals are strongly influenced by either NEE.in or ffCO2.in. Stations 4, 9, 10, and 13 are well suited in this respect. Station 4 would provide an unambiguous measure of emissions from the Los Angeles area; station 9 would sample air in the San Joaquin Valley that is effected by a mixture of agricultural and Bay Area emissions ; station 10 would be effective for monitoring signals from NEE due to Central Valley agriculture and forests in the Sierra, with a comparatively small signal from fossil $\mathrm{CO}_{2}$ emissions; station 13 would monitor exchange from northern valley agriculture and forests.

- Sampling frequency: Ideally air sampling should be conducted continuously in an automated manner to accurately capture the concentration during the well-mixed afternoon period and the diurnal variation. Data should be collected and averaged into approximately 30-minute intervals for further analysis. However, if resources are limited, periodic sampling with NOAA flask systems could be performed to provide a valuable initial data to test the model predictions similar to those performed in this study.

- Measurement protocol: Air sampling, instrument design, calibration, and analysis should follow established methods to ensure accuracy and minimize systematic errors (Bakwin et al. 1995). In particular, continuous measurements should be calibrated against multiple known standards (preferably supplied by NOAA) several times per day. Periodic sampling with NOAA flask systems should be performed at these sites to provide a check on the continuous measurements.

- Additional stations: Observations are planned for a variety of platforms to monitor background air entering California for carbon cycle and air quality purposes. This will likely include the three planned marine stations planned by NOAA, periodic aircraft profiling planned by NOAA for Trinidad Head and a site in Southern CA, and potentially 
continuous or flask sampling from one or more mountain-top stations. As noted above, interpreting signals from the marine stations will require estimation of signals from terrestrial sources in North America. It is also expected that existing flux measurement sites will be augmented with accurate and precise $\mathrm{CO}_{2}$ concentration measurements. These data sets should be included in future analyses.

\subsection{Uncertainty Analysis and Site Optimization}

Because it was beyond the scope of the current work, we did not include an analysis of the uncertainty in NEE that could be obtained using data from the suggested observing stations in an inverse approach. Before implementing a full set of observing stations, an analysis of the likely uncertainty in estimating NEE using atmospheric concentration data is warranted. In particular, one should determine whether the uncertainty in estimating NEE using the atmospheric inverse approach is very large or an infeasible number of stations are required. This is a complicated problem because the choice of the inverse approach and multiple sources of uncertainty all affect the final uncertainty in $\mathrm{CO}_{2}$ flux as well as the optimal locations for a given number of stations. In particular, the desired spatial resolution of the NEE estimates will depend on the number and locations of the stations. Sources of (likely correlated) uncertainty include: 1) the a priori NEE estimate, 2) the meteorology and hence atmospheric transport, 3) the background $\mathrm{CO}_{2}$ concentrations from outside the modeling domain, 4) the $\mathrm{CO}_{2}$ contribution from fossil emissions, and 5) the uncertainty in the concentration measurements themselves. To address these issues we recommend:

- First, simplify the consideration to focus on the uncertainty in estimating the total NEE from inside California. Use simplified forms (assume errors are uncorrelated) for the uncertainties from each of the five above sources, apply a Monte Carlo approach to generate pseudo data, and then estimate the distribution of California NEE obtained from applying an inverse method. Iterate this calculation with different combinations of towers or alternate locations to estimate the optimal number and location of towers, in part driven by budget considerations. This approach would probably provide a good first guess as to whether acceptable uncertainties in NEE for California could be obtained with a limited number of towers and hence whether and where to proceed with instrument deployment.

- Second, improve the understanding of each of the five above sources of uncertainty. For example, predictions of $\mathrm{CO}_{2}$ concentrations should include calculation of signals from the seasonally and spatially varying global background of $\mathrm{CO}_{2}$ concentrations. First order estimates in boundary conditions could be derived from the CMDL Globalview $\mathrm{CO}_{2}$ product (http://www.cmdl.noaa.gov/ccgg/globalview/index.html). These estimates should be compared with the results of aircraft campaigns that measure the vertical profile of $\mathrm{CO}_{2}$ (and other gases) over the Eastern Pacific. Estimating the boundary conditions will also be valuable because it will allow a comparison between predicted $\mathrm{CO}_{2}$ concentrations and those measured at existing stations.

- Third, expand the time periods covered in the investigation and the spatial resolution of the inverse estimates. Include several complete annual cycles to sample different weather patterns over multiple years which capture inter-annual variations in both meteorology and 
NEE (which is strongly dependent on meteorological forcing). Investigate how well NEE from different regions within California can be separately identified.

\subsection{Additional Trace Gas Species for $\mathrm{CO}_{2}$ Source Attribution}

Although it is beyond the scope of this study to analyze this problem in detail, there are several additional trace-gas species that would provide important additional constraints on $\mathrm{CO}_{2}$ exchange:

- $\mathrm{CO}$ and certain organic compounds (e.g., $\mathrm{C}_{2} \mathrm{H}_{2}$ ) have been identified as useful tracers of combustion (Potosnak et al. 1999) and should be developed for use in California, as is currently the case at Blodgett Forest. The use of CO (and other pollutant) measurements from the California Air Resources Board (CARB) might play a valuable part in this effort, particularly near urban areas where pollutant concentrations are high enough to be clearly detected with the available instruments. If dedicated future $\mathrm{CO}_{2}$ measurement stations are commissioned, inclusion of precise monitoring $\mathrm{CO}$ (and other species) in addition to $\mathrm{CO}_{2}$ would significantly enhance their capability.

- Radiocarbon $\mathrm{CO}_{2}\left({ }^{14} \mathrm{CO}_{2}\right)$ can provide a strong constraint on fossil fuel combustion because the 5700 year half-life for ${ }^{14} \mathrm{C}$ is short compared to the age of geologically derived petroleum hydrocarbons and fossil hydrocarbons contain no ${ }^{14} \mathrm{C}$. Given the current precision and accuracy of ${ }^{14} \mathrm{CO}_{2}$ measurements, it should be possible to quantify the ${ }^{14} \mathrm{CO}_{2}$ free component of air to $\sim 1 \mathrm{ppm}$. NOAA CMDL and LBNL are independently initiating the use of atmospheric sampling and analysis of ${ }^{14} \mathrm{CO}_{2}$ for this purpose. Because of the high cost for precision analysis (roughly $\$ 300$ per sample) this approach is currently beyond the scope of most routine monitoring programs, but might be employed to add precision to fossil $\mathrm{CO}_{2}$ estimates during an intensive measurement period.

- The ratio of $\mathrm{CO}_{2}$ to ${ }^{222} \mathrm{Rn}$ has been used to estimate net regional $\mathrm{CO}_{2}$ exchange using the assumption that surface emission rate of ${ }^{222} \mathrm{Rn}$ can be accurately determined (Biraud et al. 2000; Biraud et al. 2002). This technique is well suited to the problem of CA carbon budgets because much of the air entering $\mathrm{CA}$ is of oceanic origin and will be depleted in

${ }^{222} \mathrm{Rn}$. Application of this technique will require detailed analysis of ${ }^{222} \mathrm{Rn}$ source fields for CA because work has shown that ${ }^{222} \mathrm{Rn}$ emissions from soil can vary substantially with meteorology and soil moisture (Conen et al. 2002; Levin et al. 2002).

\subsection{Synthesis of Bottom-Up and Top-Down Methods}

A crucial aspect of using atmospheric, or "top-down", methods to monitor California's $\mathrm{CO}_{2}$ emissions will be to sensibly incorporate "bottom-up" information (e.g., ecosystem production from forest inventories and crop yields, fossil $\mathrm{CO}_{2}$ emissions from improved inventory methods, eddy covariance $\mathrm{CO}_{2}$ flux data from towers and aircraft flights, and ecosystem models of $\mathrm{CO}_{2}$ exchange) in the inversion. This approach is an emerging area and developments in the NACP will be valuable to addressing these issues in CA. 


\subsection{Potential for Monitoring Non-CO $\mathrm{CO}_{2}$ GHG Emissions}

The approach that we have applied here could also be profitably applied to quantify the atmospheric signals generated by surface emission of non- $\mathrm{CO}_{2}$ GHGs. Because the relative uncertainties for fluxes of non- $\mathrm{CO}_{2}$ GHGs are considerably larger than for $\mathrm{CO}_{2}$ (Franco 2002), atmospheric budget (Biraud et al. 2002) and inverse approaches may be particularly effective in significantly reducing those uncertainties using atmospheric observations. 


\section{References}

Bakwin, P. S., K. J. Davis, C. Yi, S. C. Wofsey, J. W. Munger, L. Haszpra and Z. Barcza (2004). Regional carbon dioxide fluxes from mixing ratio data. Tellus B 56(4): 301-311.

Bakwin, P. S., P. P. Tans, D. F. Hurst and C. L. Zhao (1998). Measurements of carbon dioxide on very tall towers: results of the NOAA/CMDL program. Tellus Series B-Chemical \& Physical Meteorology 50(5): 401-415.

Bakwin, P. S., P. P. Tans, C. L. Zhao, W. Ussler and E. Quesnell (1995). Measurements of Carbon Dioxide on a Very Tall Tower. Tellus Series B-Chemical \& Physical Meteorology 47(5): 535-549.

Baldocchi, D., et al. (2001). FLUXNET: A new tool to study the temporal and spatial variability of ecosystem-scale carbon dioxide, water vapor, and energy flux densities [Review]. Bulletin of the American Meteorological Society 82(11): 2415-2434.

Betts, A. K. and J. H. Ball (1998). Fife Surface Climate and Site-Average Dataset 1987-89. Journal of the Atmospheric Sciences 55(7): 1091-1108.

Biraud, S., et al. (2002). Quantification of carbon dioxide, methane, nitrous oxide and chloroform emissions over Ireland from atmospheric observations at Mace Head. Tellus Series B-Chemical and Physical Meteorology 54(1): 41-60.

Biraud, S., et al. (2000). European greenhouse gas emissions estimated from continuous atmospheric measurements and radon 222 at Mace Head, Ireland. Journal of Geophysical Research-Atmospheres 105(D1): 1351-1366.

Bonan, G. B. (1995). Land-atmosphere $\mathrm{CO}_{2}$ exchange simulated by a land surface process model coupled to an atmospheric general circulation model. Journal of Geophysical Research (Atmospheres) 100(D2): 2817-2831.

Bonan, G. B. (1996). A land surface model (LSM version 1.0) for ecological, hydrological, and atmospheric studies: Technical description and user's guide. Boulder, CO, NCAR: 150.

Bonan, G. B., K. J. Davis, D. Baldocchi, D. Fitzgerald and H. Neumann (1997). Comparison of the NCAR LSM I land surface model with BOREAS aspen and jack pine tower fluxes. Journal of Geophysical Research 102(C12): 29,065-29,076.

Bullock, O. R. and K. A. Brehme (2002). Atmospheric mercury simulation using the CMAQ model: formulation description and analysis of wet deposition results. Atmospheric Environment 36(13): 2135-2146.

Chen, F. and J. Dudhia (2001). Coupling an advanced land surface-hydrology model with the Penn State-NCAR MM5 modeling system. Part II: Preliminary model validation. Monthly Weather Review 129(4): 587-604.

Ciais, P., P. P. Tans, M. Trolier, J. W. C. White and R. J. Francey (1995). A Large Northern Hemisphere Terrestrial Co2 Sink Indicated by the C-13/C-12 Ratio of Atmospheric Co2. Science 269(5227): 1098-1102.

Cohn, R. D., B. K. Eder, S. K. Leduc and R. L. Dennis (2001). Development of an aggregation and episode selection scheme to support the Models-3 Community Multiscale Air Quality model. Journal of Applied Meteorology 40(2): 210-228.

Conen, F. and L. B. ROBERTSON (2002). Latitudinal distribution of radon-222 flux from continents. Tellus B 54(2): 127-133.

Cooley, H. S., W. J. Riley, M. S. Torn and Y. He (2004). Impact of agricultural practice on regional climate in a coupled land surface mesoscale model. in Press J. Geophys. Res. 
Crisp, D., et al. (2004). The orbiting carbon observatory (OCO) mission. Trace Constituents in the Troposphere and Lower Stratosphere. 34: 700-709.

Denning, A. S., G. J. Collatz, C. G. Zhang, D. A. Randall, J. A. Berry, P. J. Sellers, G. D. Colello and D. A. Dazlich (1996). Simulations of Terrestrial Carbon Metabolism and Atmospheric Co2 in a General Circulation Model .1. Surface Carbon Fluxes. Tellus Series B-Chemical \& Physical Meteorology 48(4): 521-542.

Denning, A. S., D. A. Randall, G. J. Collatz and P. J. Sellers (1996). Simulations of Terrestrial Carbon Metabolism and Atmospheric Co2 in a General Circulation Model .2. Simulated Co2 Concentrations. Tellus Series B-Chemical \& Physical Meteorology 48(4): 543-567.

Desjardins, R. L., et al. (1997). Scaling up Flux Measurements for the Boreal Forest Using Aircraft-Tower Combinations. Journal of Geophysical Research-Atmospheres 102(D24): 29125-29133.

Dillon, M. B., M. S. Lamanna, G. W. Schade, A. H. Goldstein and R. C. Cohen (2002). Chemical evolution of the Sacramento urban plume: Transport and oxidation - art. no. 4045. Journal of Geophysical Research-Atmospheres 107(D5-D6): 4045.

EPA (1999). Science Algorithms of the EPA Models-3 Community Multiscale Air Quality (CMAQ) Model, EPA.

EPA (2001). Inventory of U.S. Greenhouse Gas Emissions and Sinks: 1990-1999. Washington, DC, U.S. Environmental Protection Agency.

Falge, E., et al. (2002). Phase and amplitude of ecosystem carbon release and uptake potentials as derived from FLUXNET measurements. Agricultural and Forest Meteorology 113(1-4): $75-95$.

Franco, G. (2002). Inventory of California Greenhouse Gas Emissions and Sinks: 1990-1999, California Energy Commission.

Gerbig, C., J. C. Lin, S. C. Wofsy, B. C. Daube, A. E. Andrews, B. B. Stephens, P. S. Bakwin and C. A. Grainger (2003). Toward constraining regional-scale fluxes of CO2 with atmospheric observations over a continent: 2 . Analysis of COBRA data using a receptororiented framework - art. no. 4757. Journal of Geophysical Research-Atmospheres 108(D24): 4757.

Goldstein, A. H., et al. (2000). Effects of climate variability on the carbon dioxide, water, and sensible heat fluxes above a ponderosa pine plantation in the Sierra Nevada (CA). Agricultural \& Forest Meteorology 101(2-3): 113-129.

Grell, G., J. Dudhia and D. Stauffer (1995). A description of the fifth-generation Penn State/NCAR mesoscale model (MM5). Boulder, CO, NCAR.

Gurney, K. R., et al. (2002). Towards robust regional estimates of CO2 sources and sinks using atmospheric transport models. Nature 415(6872): 626-630.

Hayhoe, K., et al. (2004). Emissions pathways, climate change, and impacts on California. Proceedings of the National Academy of Sciences of the United States of America 101(34): 12422-12427.

Helliker, B. R., et al. (2004). Estimates of net $\mathrm{CO}_{2}$ flux by application of equilibrium boundary layer concepts to $\mathrm{CO}_{2}$ and water vapor measurements from a tall tower. JGR-Atmospheres 109: D20106.

IPCC (2001). 2001: Observed Climate Variability and Change. In: Climate Change 2001: The Scientific Basis. Contribution of Working Group I to the Third Assessment Report of the 
Intergovernmental Panel on Climate Change. New York, NY, USA, Cambridge University Press.

Kalnay, E., et al. (1996). The Ncep/Ncar 40-Year Reanalysis Project. Bulletin of the American Meteorological Society 77(3): 437-471.

Kasibhatla, P. and American Geophysical Union (2000). Inverse methods in global biogeochemical cycles. Washington, DC, American Geophysical Union.

Kistler, R., et al. (2001). The NCEP-NCAR 50-year reanalysis: Monthly means CD-ROM and documentation. Bulletin of the American Meteorological Society 82(2): 247-267.

Lamarque, J.-F. and P. G. Hess (2003). Model analysis of the temporal and geographical origin of the $\mathrm{CO}$ distribution during the

TOPSE campaign. J. Geophys. Res. 108(D4): 8354.

Law, B. E., et al. (2002). Environmental controls over carbon dioxide and water vapor exchange of terrestrial vegetation. Agricultural \& Forest Meteorology 113(1-4): 97-120.

Levin, I., et al. (2002). Observations of atmospheric variability and soil exhalation rate of radon222 at a Russian forest site. Technical approach and deployment for boundary layer studies. Tellus B 54(5): 462-475.

Lloyd, J., et al. (2001). Vertical profiles, boundary layer budgets, and regional flux estimates for $\mathrm{CO} 2$ and its $\mathrm{C}-13 / \mathrm{C}-12$ ratio and for water vapor above a forest/bog mosaic in central Siberia. Global Biogeochemical Cycles 15(2): 267-284.

Olsen, S. C. and J. T. Randerson (2004). Differences between surface and column atmospheric $\mathrm{CO} 2$ and implications for carbon cycle research - art. no. D02301. Journal of Geophysical Research-Atmospheres 109(D2): 2301.

Potosnak, M. J., S. C. Wofsy, A. S. Denning, T. J. Conway, J. W. Munger and D. H. Barnes (1999). Influence of biotic exchange and combustion sources on atmospheric CO2 concentrations in New England from observations at a forest flux tower. Journal of Geophysical Research-Atmospheres 104(D8): 9561-9569.

Riley, W. J., J. T. Randerson, P. N. Foster and T. J. Lueker (2004). The Impact of Coastal Meteorology on $\mathrm{CO} 2 \mathrm{Net}$ Ecosystem Exchange Estimates: Implications for global inversion studies. AGU December, San Francisco, CA.

Riley, W. J., C. J. Still, B. R. Helliker, M. Ribas-Carbo and J. A. Berry (2003). ${ }^{18} \mathrm{O}$ composition of $\mathrm{CO}_{2}$ and $\mathrm{H}_{2} \mathrm{O}$ ecosystem pools and fluxes in a tallgrass prairie: Simulations and comparisons to measurements. Global Change Biology 9(11): 1567-1581.

Wilkinson, R., K. Clarke, M. Goodchild and J. Reichman (2002). Preparing for Changing Climate: The Potential Consequences of Climate Variability and Change, U.S. Global Change Research Program.

Winrock (2004). Baseline Report for Forest, Range, and Agricultural Lands of California. Sacramento, California Energy Commission.

Wofsy, S. C. and R. C. Harris (2002). The North American Carbon Program (NACP), Report of the NACP Committee of the U.S. Interagency Carbon Cycle Science Program., Washington, DC: US Global Change Research Program.

Xu, L. K. and D. D. Baldocchi (2004). Seasonal variation in carbon dioxide exchange over a Mediterranean annual grassland in California. Agricultural \& Forest Meteorology 123(1-2): 79-96. 


\section{Glossary}

$\begin{array}{ll}\text { ABL } & \text { Atmospheric Boundary Layer } \\ \text { CARB } & \text { California Air Resources Board } \\ \text { CMAQ } & \text { Community Multiscale Air Quality Model } \\ \text { CO } & \text { Carbon Monoxide } \\ \text { CO }_{2} & \text { Carbon dioxide } \\ \text { EPA } & \text { U.S. Environmental Protection Agency } \\ \text { GHG } & \text { Green House Gas } \\ \text { IPCC } & \text { Intergovernmental Panel on Climate Change } \\ \text { LADCO } & \text { Lake Michigan Air Director Consortium } \\ \text { NACP } & \text { North American Carbon Program } \\ \text { NCEP } & \text { National Center for Environmental Prediction } \\ \text { NEE } & \text { Net Ecosystem Exchange } \\ \text { NEI } & \text { EPA National Emission Inventory } \\ \text { NOAA CMDL } & \text { and Diagnostics Laboratory } \\ \text { PIER } & \text { Nablic Interest Energy Research } \\ & \text { E.S }\end{array}$




\section{Appendix A. Diurnal and Seasonal Variations in NEE}

Figure A1 shows the diurnal variation in NEE for each ecosystem type in June. Black points indicate the average from all pixels in each day while the red bar indicates the mean (length indicating and standard error of the mean) over the 12 days included in the average. With the exception of (dryland) shrub, the ecosystems take up significant amounts of carbon during the day because temperatures are reasonably warm and water is not seriously limiting and release carbon back the atmosphere at night. The seasonal variation in NEE for the four months included in the simulations are shown in figure A2. Forest, woody savanna, grassland, and shrub ecosystems show seasonal patterns of NEE a combination of sunlight, temperature and moisture responses but are considered to be near carbon balance on an annual basis. Agriculture is modeled as a significant net sink of carbon reflecting the active removal of biomass. Irrigated agriculture is considered uniformly well watered and hence does not experience any water limitation.
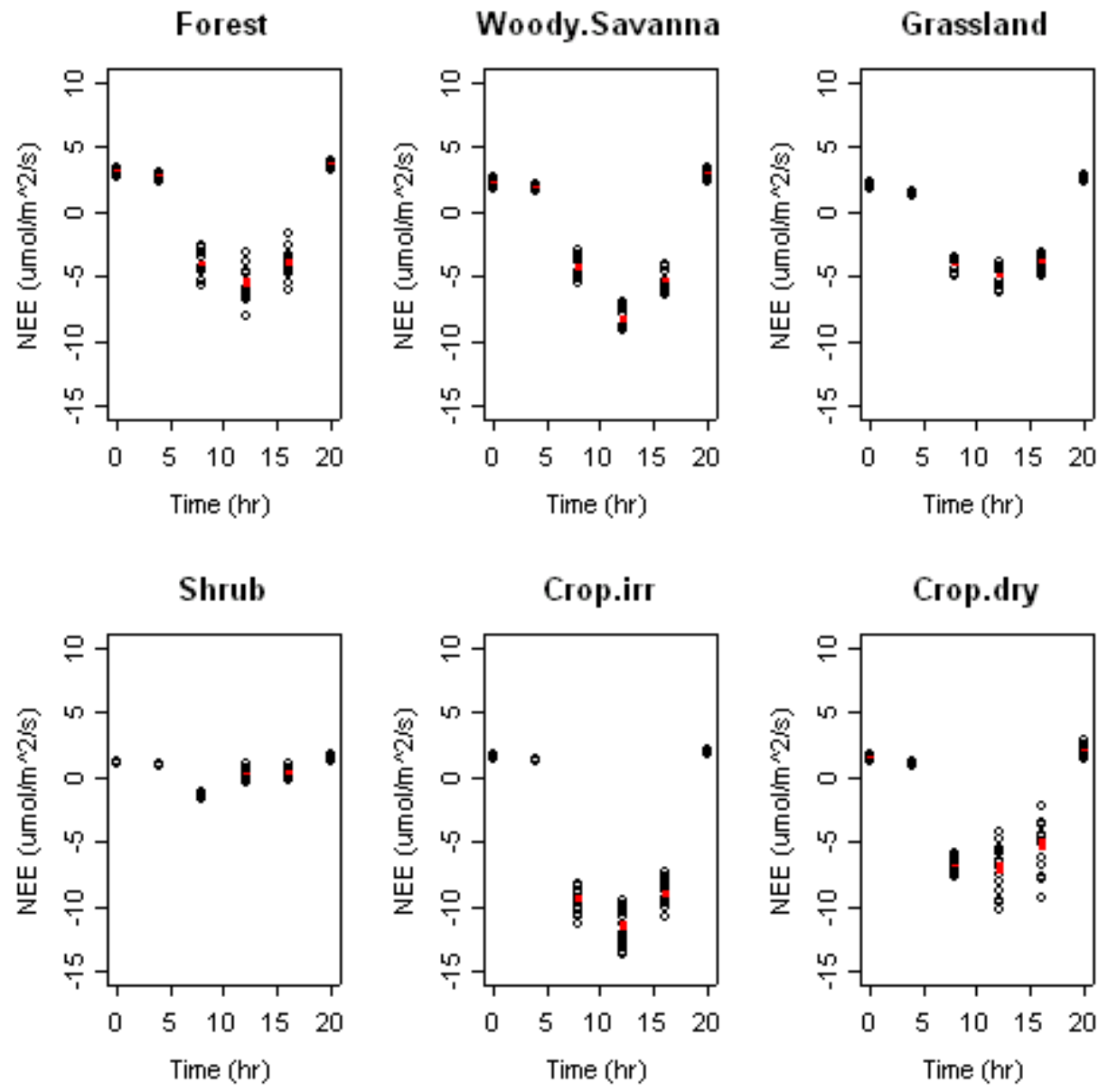

Figure A1 Diurnal variation in June NEE. 

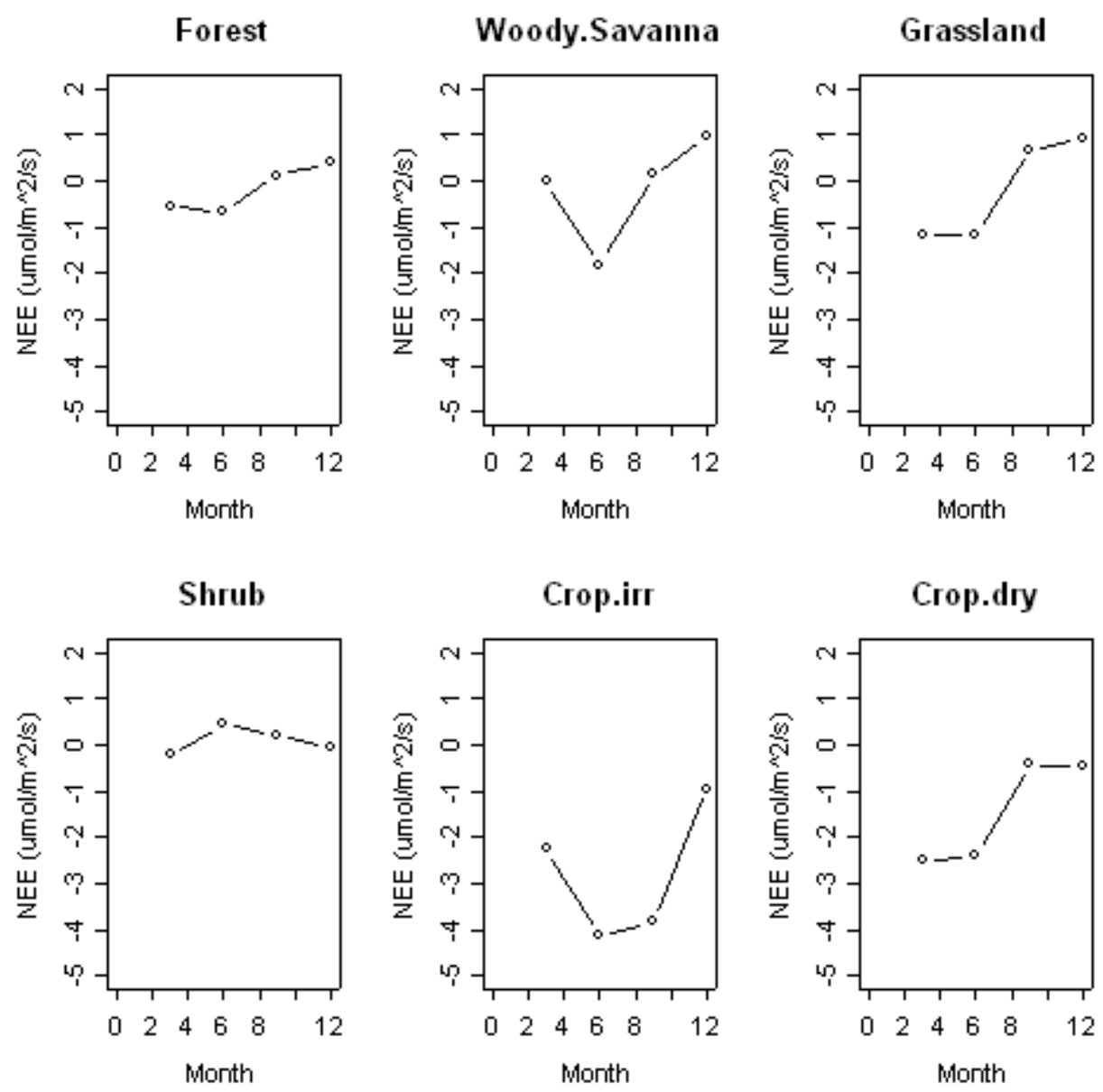

Figure A2. Seasonal variation in daily mean NEE.

\section{Appendix B. Seasonal Cycle of Mean Midday $\mathrm{CO}_{2}$ Concentration Signals}

These figures show the mean midday surface $\mathrm{CO}_{2}$ concentration signals from NEE inside CA (B1), NEE outside CA (B2), fossil fuel $\mathrm{CO}_{2}$ inside CA (B3), and fossil fuel $\mathrm{CO}_{2}$ outside CA (B4). Signals are deviations from the $\mathrm{CO}_{2}$ background from outside the modeling domain. $\mathrm{CO}_{2}$ signals from NEE show strong seasonality signals due to ecosystem exchange, while signals from fossil fuel $\mathrm{CO}_{2}$ show the direction of the mean wind (e.g. predominantly from the north in March), and the amount of mixing relative to average flow. In general, signals from NEE inside CA are large enough to be measured with standard instrumentation at many terrestrial locations. 

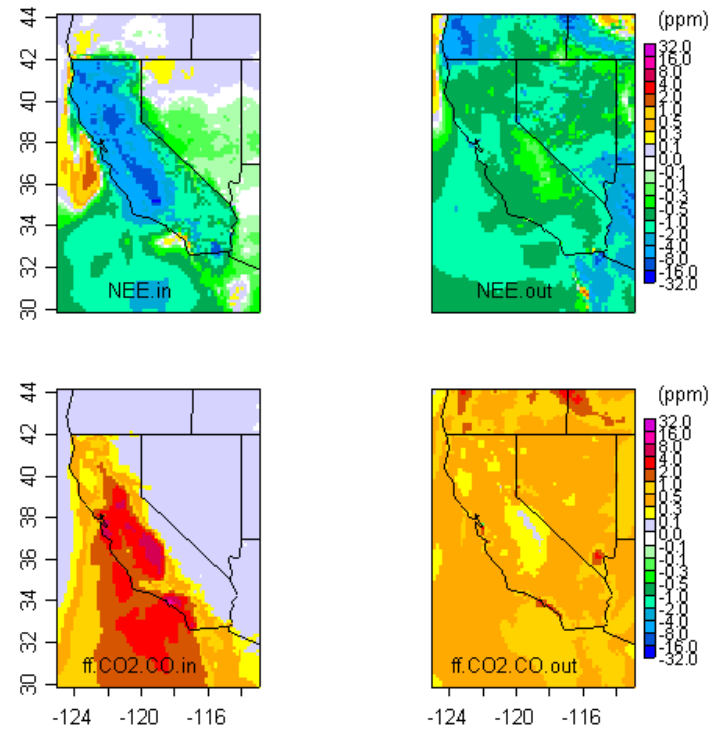

Fig B1. Signals in March.
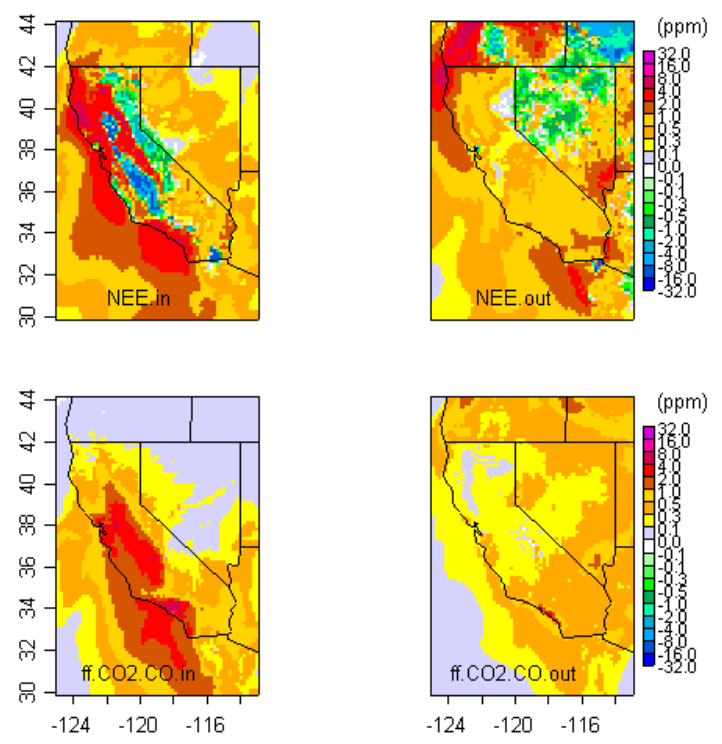

Fig B3. Signals in September.
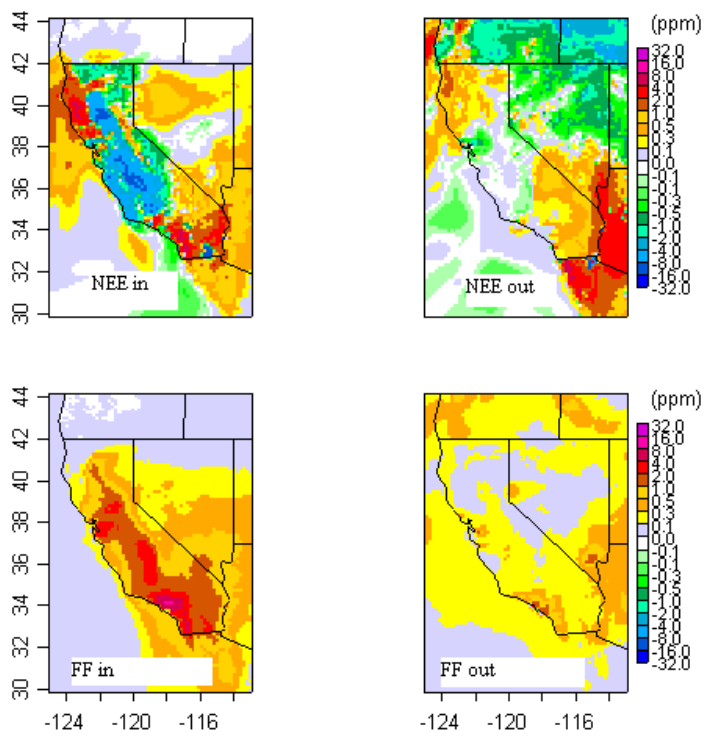

Fig B2. Signals in June (as in Fig6).
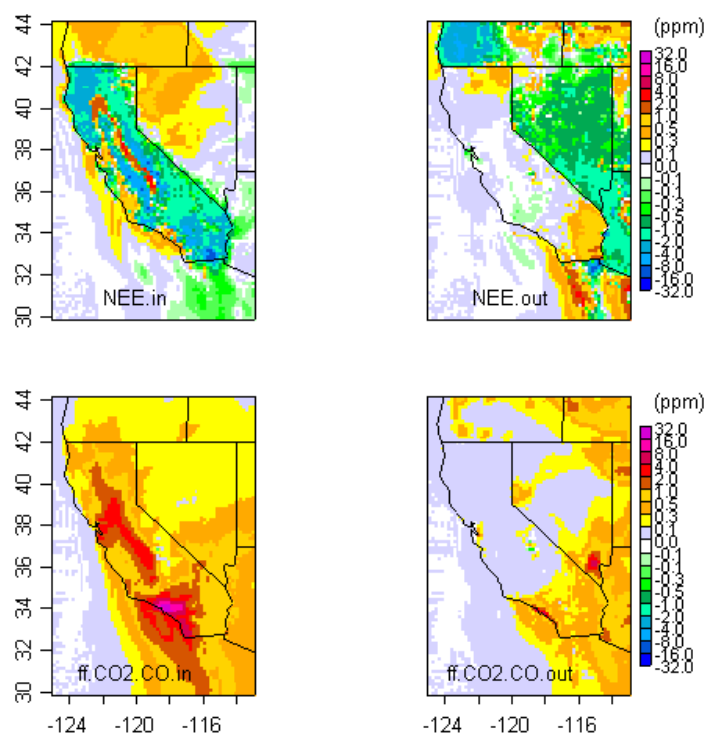

Fig B4. Signals in December. 


\section{Appendix C. Seasonal Cycles of Mean Midday Concentration Signals at Observing Stations}

The seasonal cycle of mean midday concentration $\mathrm{CO}_{2}$ signal for each source and observing station are shown in the figure below. For each observing station, the seasonal cycle in $\mathrm{CO}_{2}$ signal is shown by lines connecting symbols with a common station number. Seasons are ordered March, June, September, December. The standard error of each mean midday value is shown as a thick vertical line. Signals from NEE.in show large seasonal variations because NEE varies with ecology, climate, and atmospheric transport. Signals from fossil fuel combustion show smaller seasonal variations that are caused largely by variations in atmospheric transport.
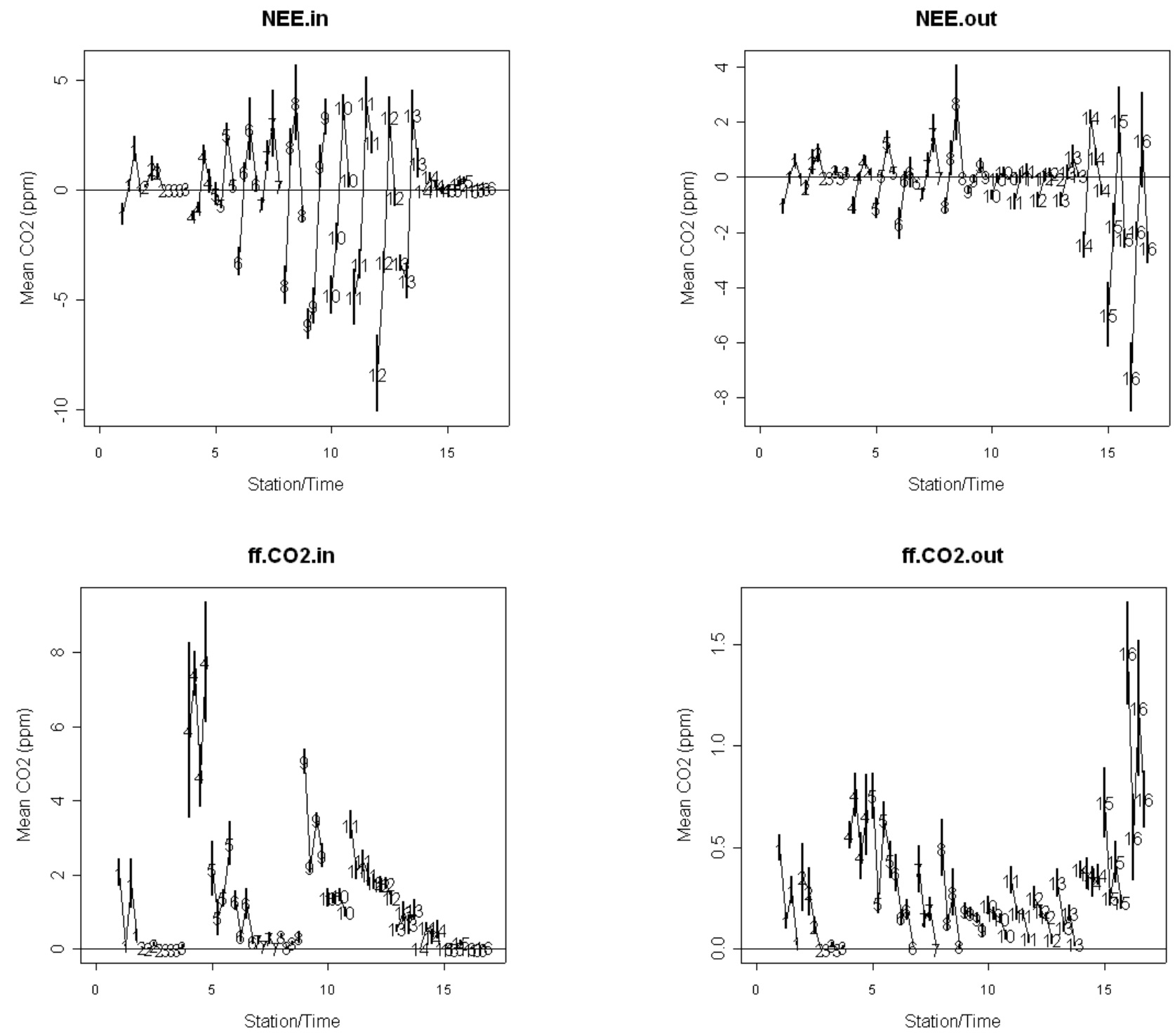